\title{
Virtus: fundamento, clave y eje de la educación política en la Edad Moderna. La válida respuesta de Thomas Fitzherbert (1552-1640) a la deconstrucción maquiaveliana
}

\author{
Virtus: foundations, keystone and axis of Early Modern \\ political education. The valid response of Thomas \\ Fitzherbert (1552-1640) to Machiavellian deconstruction
}

\section{Lía ViguRIa GUERENDIÁIN \\ GEMYR - UNED \\ https://orcid.org/oooo-0oo1-6675-8656 \\ lia.viguria@gmail.com}

Resumen:1513 representa el inicio de una convulsa etapa en el pensamiento político. Maquiavelo y sus secuaces políticos abandonan la referencia a Dios y a la naturaleza, base del orden antropológico y social desde siglos. En lo pedagógico, sin reparos, enseñan torcidas habilidades de supervivencia en el poder. Fitzherbert experimenta vivencial e intelectualmente este derribo. Se resiste a la reclusión antropocéntrica. Escribe An sit utilitas in scelere para reivindicar el poder de la virtus como dignidad, modo e instrumento del gobernante. Su enseñanza muestra la virtus como única palestra en la que a todo príncipe merece la pena adiestrarse

Palabras clave: Virtus, Thomas Fitzherbert, educación política, Nicolás Maquiavelo, razón de estado. 
La presente aportación ${ }^{1}$ pretende revelar a Thomas Fitzherbert y a su única obra escrita en latín; ambos han pasado desapercibidos durante casi cuatro siglos ${ }^{2}$. Desde la primera lectura de An sit utilitas in scelere, descubrimos a un hombre de gran notoriedad intelectual, comprometido -con pasión-con las nobles causas de la conciencia, la patria y la fe. Y el opusculum (no por breve, sino por ser la síntesis de una obra de mayor extensión y envergadura académica del mismo autor), constituyen un relevante jalón en la historia de la educación política ${ }^{3}$.

An sit utilitas in scelere ${ }^{4}$, en su forma abreviada, es un verdadero tratado de pedagogía, concebido por Fitzherbert for the benefite of young statists. ${ }^{5} \mathrm{El}$ núcleo, eje vital y conceptual lo constituye la virtus. Ciertamente el tratado la muestra $a$

1 En el marco de investigación del Grupo de Estudios Medievales y Renacentistas, GEMYR, me fue ofrecida la ocasión de trabajar sobre An sit utilitas in scelere, obra catalogada para su edición crítica y el estudio de su autor. La investigación se inserta a su vez en el proyecto de la Agencia Estatal de Innovación EDU2016-79080-R, encaminado a rescatar obras y tratados de pedagogía del humanismo.

2 Decimos que Thomas Fitzherbert y su obra han pasado desapercibidas. Entre sus oponentes, especialmente en Inglaterra, su obra completa fue silenciada por motivos religiosos y políticos. Tuvo algunos sinceros admiradores, pero el exilio y su fe católica hizo que sus adversarios lo relegaran: «he remained so great a part of his life an exile, and under the imputation of being an enemy to his country», ver Kippis, n. 27. Respecto a An sit utilitas in scelere, se añade el hecho de su redacción en latín. Entre quienes le apreciaron, la causa de no brillar en el plano académico se debe principalmente a la decisión del propio autor: empieza a escribir a los cincuenta y cuatro años y se dedica a ello sólo otros ocho. Sus obras señeras aparecen entre 1606 y 1610. Desde el momento en que ingresa en la Compañía de Jesús, 1613, pasa a dedicarse plenamente a una labor educativa y relega su carrera intelectual. Lo que escribe después de esta fecha es porque se lo solicitan, mayoritariamente en inglés, para defender posiciones de católicos ingleses frente a las injustas leyes que se van promulgando bajo Jacobo I.

3 Fitzherbert acierta a recuperar la tradicional virtus desde su fundamento originario en la naturaleza, sin exigir el componente religioso cristiano. Éste, por supuesto, añade una dimensión de mayor luz, hondura y riqueza moral cara al fin religioso del hombre. Pero Dios, al obrar sólo a través de causas segundas, deja al hombre que gobierne, protagonista libre -sin libertad no se puede hablar de virtus - y responsable, cuyos éxitos o fracasos no pueden atribuirse ni a Dios ni a Fortuna.

4 Tal como se reproduce en la página de título de la edición de 1610, el nombre completo de la obra es: An sit vtilitas in scelere vel de infelicitate principis Macchiauelliani, contra Macchiauellum et politicos eius sectatores. Autore D. Thoma Fitzherberto, nobili Anglo Sacerdote. Ad illustriss. et excellentiss. principem D. Franciscum de Castro, comitem de Castro, Ducem Taurisanum etc., Romae, apud Gulielmum Facciottum, MDCX.

5 Expresión que forma parte del propio título: The first part of a treatise concerning policy, and religion Wherein the infirmitie of humane wit is amply declared, with the necessitie of Gods grace, and true religion for the perfection of policy; and by the way some political matters are treated; diuers principles of Macchiauel confuted... with a confutation of the arguments of atheists, against the prouidence of God... Written by Thomas Fitzherbert Esquire, and Catholique priest, for the benefite of young statists, Dowai, Laurence Kellam. M. DC. VI. 
contrario, por oposición al scelus. Y esto porque el autor se ha propuesto positivamente destruir las ideas defendidas por Nicolás Maquiavelo en Il Principe, tan difundidas en las diversas cortes europeas de facto, peor, incluso, de iure ${ }^{6}$.

\section{SEMBlanZA DE ThOMAS FITZHERBERT}

El linaje de los Fitzherbert ${ }^{7}$, documentado por escrito ya desde 1125 , se remonta a los años de la conquista normanda de Inglaterra. Hasta llegar a nuestro autor, las fuentes registran trece antecesores masculinos por línea directa. Raigambre pues antiquísima, en la que tanto la fe como tierras y propiedades no han sufrido grandes deterioros... hasta la ruptura con Roma y los años de nuestro autor.

De la savia de esta estirpe, nace en 1552 en Stafford, Inglaterra, Thomas Fitzherbert ${ }^{8}$. Fallece en Roma en 1640. Una fecundísima vida que transcurre en épocas enmarcadas por el entorno geográfico en el que se desarrolla, y por un antes y un después: el exilio forzado y forzoso pero aceptado deliberadamente para servir mejor vivo que muerto.

Los años de Inglaterra -que abandona para siempre en 1582- forjan su persona. La primera etapa del exilio transcurre en París, junto a su esposa e hijos. A finales de los 90 y hasta 1602, se encuentra en España al servicio de Felipe II y después de Felipe III. Por último, los años de Roma hasta el final de su vida. Salvo dos años de permanencia en Bruselas entre 1516-1518 ${ }^{9}$, su vida intelectual y altura moral dejan en la Urbe una fecunda huella.

6 Sólo como muestra, nombramos Suppression of Religious Houses Act 1535 (27 Hen 8, c 28) y Suppression of Religious Houses (Act 1539, c. 13). El Parlamento de Inglaterra emanó ambas leyes; sucumbió a los deseos de Enrique VIII y a las consecuencias esperables tras asumir éste la jefatura de la Iglesia de Inglaterra. Las actas ordenan la supresión de conventos, monasterios y abadías de la iglesia católica de Inglaterra: se confiscaron todos los bienes y conllevó la disolución de todas las casas.

7 Ver Bede CAMM, Forgotten Shrines: an Account of some old Catholic Halls and Families in England, and of Relics and Memorials of the English Martyrs, London, 1910, pp. 1-74. Estas páginas (The Tragedy of the Fitzherberts) constituyen una buena recopilación de los datos disponibles hasta su redacción. Las fuentes proceden también de archivos familiares que el autor consultó y fotografió.

8 Para esta semblanza utilizamos datos de anteriores artículos firmados por la investigadora de la presente aportación. Al tiempo que avanzaba el trabajo sobre Thomas Fitzherbert y An sit utilitas in scelere, se han ido recabando nuevas noticias, que han completado o modificado las anteriores. Los artículos aludidos se pueden leer en la bibliografía que se añade al final del trabajo.

9 Henry More, primer biógrafo de Fitzherbert, no explícita las fechas. Henry MoRE, Historia missionis Anglicanae Societatis Iesu, ab anno salutis, M.D. LXXX ad DCXIX et vice-provinciae primum, tum provinciae ad eiusdem saeculi annum XXXV collectore Henrico Moro, eiusdem Societatis Sacerdote, 1660, 


\section{LÍA VIGURIA GUERENDIÁIN}

\section{Antes del exilio, en Inglaterra}

Fitzherbert se educa en la tradición católica familiar y encamina su trayectoria hacia las leyes, al igual que el abuelo Anthony ${ }^{10}$. Su padre, William, muere cuando él tiene seis años. Su madre contrae nuevo matrimonio ${ }^{11}$.

La educación intelectual es una característica del abolengo familiar. Así que los Fitzherberts no frenan la llamativa curiosidad intelectual de Thomas; al contrario, la fomentan. Además se le dan bien los libros.

\section{De 1566 a 1582 en Oxford y Londres}

La inquietud intelectual de Fitzherbert se dispara, por así decir, al llegar a Oxford. En una positio sobre Campion, relata cómo circulaban copias de sus disertaciones y él podía leerlas ${ }^{12}$ :

About the year of our Lord 1567, I knew Father Campion, of blessed memory, in Oxford, who was then Master of Arts (which degree in that University is as much as Doctor in Artibus here [in Rome]), and was famed for his eloquence, in which respect he was made Junior of the Act, when he proceeded Master of Art, which place or title is always given to the best orator of those who take degree at that time. And for the opinion and fame which he had for his eloquence, the orations which he made in the University upon occasions then occurring, were diligently copied and greatly desired by all the scholars of the University, whereof I myself saw some copies at that time.

Audomari (Saint-Omer), pp. 235-242. Sí las apunta Henry FOLEY en Records of the English province of the Society of Jesus: Historic facts illustrative of the labours and sufferings of its members in the sixteenth and seventeenth centuries. Second, Third and Fourth Series, London, 1875, t. 1, p. 207. También Foley propone la de 1618 como año del inicio de nuestro autor en el cargo de Rector del Colegio Inglés de Roma.

10 Juez de gran prestigio en su época, se le conocía como the great lawyer. Se opuso abiertamente al cardenal Wolsey ante la confiscación de bienes de la Iglesia entre 1524 y 1529 . Fue uno de los magistrados del tribunal que sentenció a Tomás Moro a pena de muerte, hecho éste que marcó moralmente a toda la familia.

11 El padre de Thomas murió en 1558. De su mujer había recibido the Manor of Swynnerton, que acabó siendo patrimonio de la descendencia de nuestro autor. Al cabo de unos años, su madre contrajo nuevo matrimonio con John Gatacre. John BURKE, A Genealogical and Heraldic History of the Commoners of Great Britain and Ireland, Enjoying Territorial Possessions or High Official Rank, but Uninvested with Heritable Honours, t. 1, London, 1833, p. 82.

12 John Hungerford Pollen, Acts of English martyrs hitherto unpublished, London, 1891, p. 35. 
De esta etapa de estudiante sabemos que consulta las bibliotecas con asidui$\mathrm{dad}^{13}$, también en Londres. Ésta fue una de las razones por la que Persons ${ }^{14}$ le solicitó ayuda en 1580 para la revisión de Rationes Decem de Campion. También posteriormente, en calidad de jurista, tiene fácil acceso a ellas.

En ambas ciudades vive Fitzherbert «estudiante, activista, objetor de conciencia; hombre de leyes, presidiario, reincidente clandestino». La temprana madurez de un hombre intrépido a quien el riesgo más le incita que arredra. Pero le afectan y repercuten acontecimientos que sufren su tío sir Thomas y otros familiares cercanos, que son detenidos y encarcelados por traitors, cuando en realidad son leales súbditos que confiesan sin miedo ni hipocresías sociales su $\mathrm{fe}^{15}$. Son los años en los que conoce a los primeros jesuitas ingleses, Edmund Campion y Robert Persons, que llegan a la Isla para alentar a los católicos. Fitzherbert les proporciona cobijo, revisa sus escritos y se ocupa de prensas clandestinas para publicarlos. Por ello va a la cárcel. Tras su liberación reincide, y, ante la fuerte persecución y el consiguiente peligro para sí y la familia que acaba de fundar, ha de resolver dejar Inglaterra. Efectivamente, en 1580 contrae matrimonio con Dorothy East; nace el primogénito Edward al año siguiente; Elizabeth quizá nace ya en París en $1582^{16}$.

\section{Francia, España: el exilio de un consejero político}

En 1582 Thomas y Elizabeth son ya padres de dos hijos. Residen en París, donde Fitzherbert se hace valer como consejero de Catalina de Médici y del duque de Guisa. Sufre viperinas vigilancias de espías ingleses; le tienden una trampa casi mortal de la que le libra el Duque de Feria ${ }^{17}$.

$13 \ll$ Mr. Fitzherbert was a great lover of books; and perhaps few laymen, of his time, made a better use of their academical education». Charles DODD, The Church History of England, from the Year 1500, to the Year 1688. Chiefly with Regard to Catholicks: Being a Complete Account of the Divorce, Supremacy, Dissolution of Monasteries, and First Attempts for a Reformation Under King Henry VIII... in Eight Parts, Brussels [i.e. London], 1739, t. 2, p. 412.

14 Algunos estudiosos eligen la grafía Parsons. Nosotros seguimos la que aparece en las fuentes editadas que ofrecemos más adelante.

15 Bede CAMM, Forgotten..., ver n. 7, p. 21ss.

16 Las fuentes consultadas no mencionan registros civiles ni parroquiales del matrimonio. Tampoco del nacimiento de los vástagos.

17 «Charles DODD, Church History..., 1732, ver n. 13, t. 2, p. 411. Henry FOLEY, Records..., ver n. 9, p. 202. Lorenzo IV Suárez de Figueroa y Córdoba (1559-1607), II duque de Feria (1571-1606) y I marqués de Villalba (1567-1607). Badajoz, 1560 / Nápoles (Italia), 1607. Embajador de Felipe II 


\section{LÍA VIGURIA GUERENDIÁIN}

Muere la esposa de Thomas Fitzherbert en 1588. Entonces nuestro autor se predispone a iniciar un nuevo recorrido vital; pero tendrá que esperar unos quince años para poder realizarlo.

Con Felipe II desde 1596 y Felipe III es Secretario para los Asuntos de Inglaterra ${ }^{18}$. Su antecesor, Francisco Inglefield, muy enfermo, propone al Rey que le suceda en el cargo $^{19}$ :

Importara tambien al servicio de V.M., que algun hombre confidente y intelligente de nuestra nacion ressida en Madrid, para dar avisos a V.M., y a los de su consejo, mucho mejor de lo que yo he pedido hazer: y, al presente, viene a España, con el duque de Feria, un cavallero muy principal, llamado Tomas Fitzherbert, que ha servido muchos años a V.M., con grande satisfaccion, y es de grande fidelidad y partes, y de casa muy principal: y si V.M. fuere servido honrarle y armarle cavallero al modo de Inglaterra, y darle la casa y entretenimientos que yo hasta agora he tenido, seria animar mucho a el, y a los buenos de nuestra nacion; y sin duda entiendo, que seria mucho servicio de V.M.: -y por esto se lo propongo y suplico humildemente a V.M., a quien nuestro Señor de muy largos años prosperos de vida como le suplico. En Valladolid, estando muy apretado de calenturas, a 8. de 7 bre 1596.

De v. Catolica Magd.

fiel subdito y criado

Francisco Englefield

y Felipe III, virrey de Cataluña y de Sicilia. Ocupó el cargo entre 1602 y 1606 y, posteriormente, se le confió la embajada del Imperio austríaco, en la corte de Rodolfo II, con motivo de los problemas que planteaba la falta de sucesión legal del Emperador y el hecho de no haberse nombrado todavía Rey de Romanos. De camino entre Nápoles y Roma, falleció en enero de 1607». Antonio FERNÁNDEZ LUZÓN en http://dbe.rah.es/biografias/15663/lorenzo-suarez-de-figueroa, accedida el 17/09/2018.

18 Léa BÉNICHOU, Informadores y confidentes de los embajadores de Felipe III en Roma, en Tiempos Modernos, t. 8, 35/2, 2017, pp. 195-196. Se refiere a la red de exiliados ingleses al servicio de la monarquía española, comprometidos a favor del restablecimiento del catolicismo en la isla en tiempos de Felipe II, siguieron sirviendo a Felipe III en el contexto de la sucesión al trono inglés y de las negociaciones de paz entre Inglaterra y España que desembocaron en la firma del tratado de Londres, el 28 de agosto de 1604. Y su nota 34: «Véase Albert Joseph LOOMIE, The Spanish Elizabethans. The English Exiles at the Court of Philip II, New York, Fordham University Press, 1963. Thomas M. MCCOOG, The Society of Jesus in Ireland, Scotland, and England, 1589-1597: building the faith of Saint Peter upon the King of Spain's monarchy, Farnham, Ashgate, 2012».

19 «[Letters of Englefield and others, MS. vol. in my possession, f. 1.] Appendix No. XIII. (Referred to at page 30)», en Charles DODD y M. A. TIERNEY (ed.), The Church History of England, from the Year 1500, to the Year 1688, London, 1840, t. 3, pp. LII-LIII. Último asunto de esta carta que Dodd reproduce en el original castellano y traduce al inglés. Respetamos la grafía del editor. 
Sus cualidades, valía y valentía le convierten en hombre de confianza. Además, ha aprendido a medir sus riesgos. Es sereno, prudente, tamizado en sus juicios y a la vez determinado hombre de acción.

El 10 de mayo de 1595, la posible muerte del Cardenal William Allen movió a Robert Persons a escribir al mismo Englefield. Le solicitaba hablar a Felipe II para promover a Fitzherbert al cardenalato, aun sin haber recibido éste las órdenes del presbiterado. La decisión no salió adelante porque el propio Fitzherbert se interpuso ${ }^{20}$.

Desde el Consejo del rey indican a Suárez de Figueroa, duque de Feria, ahora designado virrey de Sicilia, que se haga acompañar de Fitzherbert. Pero a la muerte del duque en 1607 cesa su colaboración en el Consejo de Felipe III. La corona española le mantiene la pensión aprobada en 1602 y la residencia proporcionada junto al Colegio Inglés de Roma.

\section{Roma: $1602-1640$}

Fitzherbert, viudo y quizá algo hastiado de las cortes y el artificio, aunque ama Inglaterra, no se siente exiliado. Roma es su hogar definitivo. Culmina su deseo de ser sacerdote, el voto que se prometió a sí ante Dios, a la muerte de Do-

20 Episodio muy significativo de la actitud y fama de nuestro autor. «Opportune hic dicetur qualis vir [Fitzherbertus] et quantus is fuerit, quandoquidem Personio numerabatur inter eos quos dignos censeret, qui Alano in purpura succederent, et multis ante obitum annis Societatem complexus». Henry MORE, Historia..., ver n. 9, p. 235. Detalle que tampoco pasa desapercibido a un anglicano como à Wood. En su Athenae Oxoniensis de 1691 recoge: «He was a person of excellent parts, had a great command of his tongue and pen, was a noted Politician, a singular lover of his Country men, especially those who were Catholicks, and of so graceful behaviour and generous spirit, that great endeavours were used to have him created a Cardinal some years after Allens death, and it might have been easily effected, had he not stood in his own way», col. 538 .

Kippis, en su Biographia Britannica de 1750, dice abiertamente que, si el capelo cardenalicio hubiera sido su objetivo, lo habría recibido: «[Fitzherbert] was often named within that space of time for a Cardinal's hat, in the room of Cardinal Alan, which it is thought he might easily have obtained, if it had been in reality the object of his ambition (l). But he was a man of a mild and moderate disposition, more especially in the latter part of his life, and for that reason was more willing to decline, than to aspire to, that envied dignity. (l) Athen. Oxon, vol. I. col. 632», p. 1941. (l) La referencia que ofrece Kippis no responde a este lugar. Andrew KIPPIS, Biographia Britannica: Or The Lives Of The Most Eminent Persons Who Have Flourished in Great Britain And Ireland, From the Earliest Ages, Down to the Present Times: Collected from the Best Authorities, Both Printed and Manuscript, And Digested in the Manner of Mr Bayle's Historical and Critical Dictionary, vol. 3, London, 1750, p. 1941. 
rothy en 1588. Recibe la ordenación cuando ya se encuentra en la cincuentena ${ }^{21}$. Su temprana admiración por los jesuitas se convierte en una clara llamada de fe a su conciencia. De nuevo debe esperar. Por fin se le admite en $1613^{22}$; profesa la probación definitiva en 1614.

Pero hasta la ordenación sacerdotal siguió trabajando para Inglaterra: es el primer laico en servir como Agente para el clero secular inglés desde la Urbe. Le acusan de trato de favor a los jesuitas y se ve envuelto en la llamada controversia de los arciprestes $^{23}$. Paralelamente se le intenta mezclar en un complot contra el monarca Jacobo ${ }^{24}$. Entre tanta infamia su buen nombre se resiente. En este momento, casi entre el cielo y la tierra, decide asumir la defensa de un religioso frente a autoridades católicas en Inglaterra; e igualmente, en el asunto de la conspiración, aboga ante la justicia por el padre Garnet. Actúa en conciencia y por fidelidad a los amigos. La seriedad de su intervención (que realiza por escrito) le devuelve no sólo el buen nombre en vida, sino hasta el elogio póstumo que le brindan sus antiguos defendidos.

Sus años como jesuita no son pocos. Ya en 1616 le confían la dirección del Colegio Inglés de Bruselas ${ }^{25}$. Y desde 1618, de nuevo en Roma, es Rector del Co-

21 Henry More, Historia..., ver n. 9, pp. 236-237: «Anno sexcentesimo primo cum essem in Hispania in Festo Nativitatis eiusdem [Virginis] vovi Sacerdotio initiari, Deo et Sanctissimae Matri praestare possem obsequium: atque ea propter anno sequenti in Festo Purificationis, hic Romae, habitum indui Sacerdotalem, fuique Sacerdotio initiatus in peruigilio Annuntiationis eiuldem anni, et cecini Missam primam in ipfo Festo». Las fechas son pues: 8 de septiembre de 1601, 2 de febrero de 1602, 24 y 25 de marzo de 1602 respectivamente. Con todo, algunos biógrafos de los siglos XVI y XVII dudan entre 1601 y 1602 . George Oliver en 1838 confirma con seguridad la fecha de More. George OLIVER, Collections Towards Illustrating the Biography of the Scotch, English, and Irish Members, S.7., 1838, p. 87: «On 24th of March 1612 he was promoted in Rome to the Priesthood».

22 «Anno vero huius seculi decimo tertio palam suscepta Societatis veste, praefuit deinde Missioni Bruxellis annis duobus, et in eius temporis controversiis scripsit quae Alegambe recenset». Henry MORE, Historia..., ver n. 9, pp. 236.

23 George BIRKHEAD y Michael C. Questier (ed.), Newsletters from the Archpresbyterate of George Birkhead, vol. 12 (Camden Fifth Series), Cambridge, 1998, nota 39 a p. 8: «Cardinal Bianchetti sharply admonished Birkhead for dismissing Fitzherbert as his agent, [ $\left.{ }^{*}\right]$ AAW A IX, no. 88». [ ${ }^{*} \mathrm{Ar}-$ chives of Westminster Dioces].

24 Tras varias conspiraciones fallidas para derrocar, incluso asesinar, a Isabel I en el siglo anterior, la justicia oficial denunció en 1603 a algunos ingleses católicos de maquinar el Gunpowder Plot, intento de magnicidio de Jacobo I. Episodio histórico que sigue sin haber resuelto la culpabilidad de los implicados en la traición. Sí es cierto que muchos católicos deseaban poner fin a las leyes anticatólicas, que desde Enrique VIII se habían ido recrudeciendo.

25 Salvo estos dos años en los Países Bajos, 1616-1618, no constan otros viajes ni estancias fuera de Roma hasta su muerte. 
legio Inglés hasta pocos meses antes de fallecer. Su labor intelectual, disciplinar y magisterial reciben aprobación general. Se le recuerda en los pasillos y estancias del Colegio con cariño y admiración ${ }^{26}$. Los testimonios no provienen sólo de sus compañeros jesuitas. Ingleses no católicos, decenios más tarde, también se harán eco de su valía intelectual y moral ${ }^{27}$.

26 Thomas Courtenay, sucesor de Thomas Fitzherbert al frente del Colegio de los Ingleses en Roma, redactó una nota necrológica llena de admiración y cariño al fallecer su predecesor. Dejó así un breve, pero valiosísimo, relato biográfico y retrato moral de nuestro autor. Este escrito es base de todas las posteriores referencias a Fitzherbert. El primero en utilizar la nota de Courtenay, a los dos años de morir Thomas Fitzherbert, es Philippe DE ALEGAMBE, Bibliotheca Scriptorum Societatis Iesu, Post excusum Anno 1608 Catalogum Petri Ribadeneirae Nunc boc novo apparatu librorum ad annum reparatae salutis 1642 editorum concinnata et illustrium virorum elogiis adornata; Accedit Catalogus Religiosorum Societatis Iesu, ... / a Philippo Alegambe, 1643, Antverpiae, Apud Ioannem Meursium. En 1660, a veinte años de fallecer Fitzherbert, Henry More reproduce la nota y se refiere al registro de Alegambe sobre Fitzherbert. Una traducción al inglés de la breve nota biográfica de Courtenay se puede encontrar en An Eulogium of the Rev. F. Thomas Fitzherbert, written by F. Thomas Courtenay, Rector of the English College at Rome, the day after the said F. Fitzherbert's decease, en The Catholic Spectator, vol. 1, London, 1824, pp. 171-173.

27 Anthony à Wood afirma lo mismo a medio siglo de la muerte de Fitzherbert en Athenae Oxonienses. An Exact History of all the Writers and Bishops who have had their Education in the most Ancient and Famous University of Oxford, from The Fifteenth Year of King Henry the Seventh, Dom. 1500, to the End of the Year 1690. (...). The First Volume, Extending to the 16th. Year of King Charles I. Dom. 1640, 1691, p. 538.

Edward Kippis recoge de anteriores autores una descripción de los últimos años y muerte de Fitzherbert en el Colegio Inglés de Roma: «His body was interred in the chapel belonging to the English college at Rome. As he remained so great a part of his life an exile, and under the imputation of being an enemy to his country, he may be justly reputed unhappy, but yet less so than a near relation of his who was contemporary with him, and resided for some years in the same College, since our author lived the far greater part of his days decently, if not splendidly, and died at last peaceably in his bed, exceedingly admired by those of his own faction, and as much esteemed as he could expect by the rest of his countrymen, who disliked nothing in him but his persuasion, and were sorry that a man of his parts, learning, and politeness, should, by his obstinacy, make himself so unhappy». Edward KIPPIS, Biographia..., ver n. 20, p. 1941. Entre sus paisanos ingleses ya anglicanos parece que lo admirable de Fitzherbert se torna decepción; su fe católica y permanencia en ella les impiden enorgullecerse de él. Desde nuestro punto de vista, esta actitud explica en parte el silencio hasta el día de hoy que ha planeado sobre su persona, trabajo intelectual y escritos. También Kippis, que cita varias veces a à Wood, se hace eco del renombre de nuestro autor y de su alta talla moral. «His great parts, his extensive and polite learning, together with the high esteem that he had procured by his prudent behaviour at Brussels, procured him what any other in his situation would have esteemed a very high preferment, but which he with much reluctancy accepted. This was the Government, with the title of Rector, of the Roman College at Rome, which office he exercised with unblemished credit for twenty-two years, and was often named within that space of time for a Cardinal's hat, in the room of Cardinal Alan, which it is thought he might easily have obtained, if it had been in reality the object of his ambition». Kippis, ibid. 


\section{Biografía desde dentro}

Debemos destacar tres escritos autógrafos de Thomas Fitzherbert, los cuales constituyen una biografía desde su interior. Los recoge Henry More en un largo excurso. Ésta es la primera vez que se publican desde 1660. Cabe resaltar que More, en esta obra sobre los jesuitas en Inglaterra, dedica nada menos que ocho páginas a Thomas Fitzherbert, que nunca fue jesuita inglés. Como hemos visto, fue recibido en la Compañía cuando ya llevaba diez años en Roma. Desde que saliera al exilio en 1582, nunca regresó a Inglaterra, aunque ésta fue su intención primera.

Dada su longitud, los reproducimos íntegramente en el Anexo ${ }^{28}$. Avanzamos ahora un extracto, buen ejemplo de la talla moral de su autor. Desde el conocimiento de su profunda fe se entiende que ésta ilumine sus convicciones, decisiones y actos; también en el campo de la política. Dicha fe, que se vierte en experiencia de vida, explica a su vez su tenaz defensa de la virtus como único sello y contraste de la dignidad del gobernante, del valor de sus acciones de gobierno.

Desde aquel momento he dicho abiertamente a todos que soy católico; y donde quiera que iba defendía la religión católica contra ministros u otros herejes y confortaba a los católicos. Por ello estuve casi dos años obligado a esconderme hasta que me cogieron y me metieron en la cárcel, con gran regocijo para mí. Después de ese tiempo, vinieron a Inglaterra los Padres Campion y Persons, me uní a ellos y les servía del modo que podía; hasta que, al aumentar la persecución contra mí, decidí emigrar y vivir exiliado mientras dominara la herejía.

\section{Thomas Fitzherbert: el autor}

Con una vida diaria tan llena de sucesos heroicos y extraordinarios, es comprensible que Thomas Fitzherbert no pudiera sentarse a escribir. Así, sólo desde que se establece en Roma, lejos de las cortes reales, ya con cincuenta años, puede dedicar tiempo a reflexionar, extraer recuerdos y aprendizajes de la experiencia y ponerse a escribir para transmitirlos.

Consta que Fitzherbert sólo después de ser sacerdote comienza su andadura como escritor. Circunscribe su trabajo al ámbito académico y apologista. Es un

28 La traducción es nuestra. Se ha reflejado el tono de época y autor del original, en la medida en que resulta legible al lector de hoy. Henry MORE, Historia..., ver n. 9, pp. 236-241. 
vivo valedor de la fe y defensor de los amigos de confesar libremente la $\mathrm{fe}^{29}$. Su experiencia y su valía como consejero, así como su conocimiento y respeto de la ley han dejado clara impronta en la perspectiva y el estilo.

Antes de 1600 sólo ha colaborado en una obra apologética, Rationes Decem, salida de una imprenta clandestina en 1580. Edmund Campion, su autor, le confió a través de Persons cotejar las citas de los Padres de la Iglesia y la revisión final ${ }^{30}$.

A partir de 1602 escribe las obras de su autoría. Todas son pues de sus años de sacerdote. De ellas dos tratan contenido filosófico-pedagógico sobre religión y política. Seis obras son de carácter polémico; más bien controversias teológicas con el anglicanismo y otras herejías que responden al contexto religioso inglés; se las puede considerar apologéticas. Denuncian y refutan errores, pero sobre una labor de fundamentar las verdades y usos de la religión católica.

Podrían añadirse textos de Fitzherbert en los que defiende por escrito a reos enjuiciados en Inglaterra. O también escritos que le solicitan en la Compañía. De algunos se tienen referencias, pero el original no está repertoriado. Confiamos en que entre el material que falta por desempolvar en los archivos se hallen los referidos y otros nuevos, de modo que se puedan ir publicando.

Hacia el final de su vida, escribe el último libro, aunque no propio. Una bella traducción al inglés desde el latín sobre la vida de San Francisco Javier.

El elenco siguiente cita los títulos completos, según la editio princeps, que respetamos por ser una síntesis del contenido:

1. 1602, A defence of the Catbolyke cause contayning a treatise in confutation of sundry vntruthes and slanders, published by the heretykes, as wel in infamous lybels as otherwyse, against all english Catholyks in general, or some in particular, not only concerning matter of state, but also matter of religion: by occasion whereof diuers poynts of the Catholyke faith now in controuersy, are debated and discussed. VVritten by T.F. With an apology, or defence, of his innocency in a fayned conspiracy against her Maiesties person, for the which one Edward Squyre was wrongfully condemned and executed in Nouember... 1598. wherewith the author and other Catholykes were also falsly charged. Written by him the yeare folowing, and not published vntil now, for the reasons declared in the preface of this treatise, Amberes, Conincx.

29 Este último tema, por su relación con la verdad y la conciencia, suscita un interesantísimo objeto de estudio, que en suelo inglés ha conocido un desarrollo muy particular e intenso. Thomas Fitzherbert, junto con Thomas More y John Henry Newman. Sin cesiones a la veleidad o arbitrariedad, estos autores marcan un itinerario de reflexiones con un denso contenido filosófico y antropológico más que teológico, pero iluminadas y emanadas desde la concepción del hombre como factura divina.

30 Stonor Park, Brinkley, 1581. Fitzherbert lo relata de propia mano. Este trabajo para Campion lo menciona Edward KIPPIS, Biographia..., ver n. 20, col. 1941. 


\section{LÍA VIGURIA GUERENDIÁIN}

2. 1602, Apology or defence of his innocence in a fained conspiracy against her Majesties person, for the which one Edw. Squire was wrongfully condemned and executed, in Nov. 1598. Fue impreso en el mismo volumen junto con la precedente $A$ defence of the Catholyke cause...

3. 1606, The first part of a treatise concerning policy, and religion Wherein the infirmitie of humane wit is amply declared, with the necessitie of Gods grace, and true religion for the perfection of policy; and by the way some political matters are treated; diuers principles of Macchiauel confuted... with a confutation of the arguments of atheists, against the prouidence of God... Written by Thomas Fitzherbert Esquire, and Catholique priest, for the benefite of young statists, Douai, Laurence Kellam.

4. 1610, An sit vtilitas in scelere vel de infelicitate principis Macchiauelliani, contra Macchiauellum \& politicos eius sectatores. Autore D. Thoma Fitzherberto, nobili Anglo Sacerdote. Ad illustriss. \& excellentiss. principem D. Franciscum de Castro, comitem de Castro, Ducem Taurisanum \&c., Romae, apud Gulielmum Facciottum, MDCX.

5. 1610, The second part of a treatise concerning policy, and religion, Wherein the necessity, fruite, and dignity of christian religion, in common welth, is euidently showed, with the absurdity of false religions, and the danger, and dammage, that ensueth thereof to all states; and by the way somme philosophical, moral, and politicall matters are treated... finally it is clearely proued, that the catholique Roman religion only doth make a bappy common welth. Written by Thomas Fitzherbert Esquyre, and Catholique priest, Douai, P. Auroi, Anno Domini 1610.

6. 1612. A discussion of the ansvere of $M$. VVilliam Barlovv, D. of Diuinity, to the booke intituled: The iudgment of a Catholike Englishman liuing in banishment for bis religion $b c$. Concerning the apology of the new Oath of allegiance. VVritten by the $R$. Father, F. Robert Persons of the Society of Iesus. VVhervnto since the said Fathers death, is annexed a generall preface, laying open the insufficiency, rayling, lying, and other misdemeanour of M. Barlow in his writing. Saint-Omer ${ }^{31}$.

7. 1613, Suppliment to the discussion of $M r$. Dr. Burlows answer to the judgment of a Cath. Engl. Man, \& c. interrupted by the death of the author F. Rob. Persons Fesuit, S. Omer 1613. Publicado con las letras del autor F.T., Thomas à Wood lo atribuye a Thomas Fitzherbert sin dudar ${ }^{32}$.

8. 1613, An adioynder to the supplement of Father Robert Persons his discussion of $M$. Doctor Barlowes ansvvere \&oc. Contayning a discouery, and confutation of very many foule absurdityes, falsities, and lyes in M. D. Andrewes bis Latin booke intituled, Responsio ad apologiam Cardinalis Bellarmini ofc. An answere to the apology of Card. Bellarmine. Written by F.T... Also an appendix touching a register alleaged by M. Franc.

31 A la muerte de Robert Persons en 1610, escribe una respuesta en defensa de una obra de éste que, tras su publicación en 1608, fue refutada por el profesor de Divinity, Mr. Barlow. El título recoge el contenido de la entera controversia y los documentos a los que se alude. Thomas Fitzherbert es el autor del prefacio y a él se debe la autoría intelectual que Persons le solicitó para los pasajes de contenido jurídico.

32 Anthony Á WoOD, Athenae..., ver n. 27, p. 538. 
Mason for the lawfull ordayning of Protestant bishops in Q. Elizabeths raigne, SaintOmer, English College Press.

9. 1613, Censure of Dr. Foh. Donnes book intit. Pseudo-Martyr, Saint-Omer, English College Press. Este último publicado en el mismo volumen junto con el precedente.

10. 1614, The reply of T. F. in defence of the two first chapters of his Supplement to the discussion orc. impugned by one falsely naming bimself Roger Widdrington, in a Latin booke intituled, Disputatio de iuramento fidelitatis... 1614, Saint Omer.

11. 1621, The obmutesce of F.T. to the Epphata of D. Collins. Or The reply of F.T. to D. Collins his defence of my Lord of VVinchesters answere to Cardinall Bellarmines Apology, In which reply $M$. Collins is conuinced of most manifest frauds, falsityes, fooleryes, \& lyes. Written by Thomas Fitzherbert Priest of the Society of Iesus, in defence of bis adioynder impugned by $M$. Collins: wherein the authors name was cyphred with the two letters F.T., Saint-Omer, English College Press.

12. 1632, The admirable life of S. Francis Xavier, Deuided into VI. bookes written in Latin by Fa. Horatius Tursellinus of the Society of Iesus and translated into English by T.F., Saint-Omer, English College Press ${ }^{33}$.

Las obras que le dieron nombre son An sit utilitas in scelere y Treatise concerning Policy and Religion. Henry More, nos deja un breve pero jugoso comentario sobre ellas ${ }^{34}:$ «Primum edidit latine contra Machiavellum de hac thesi, An sit utilitas in scelere? doctum opus et pium. Tum Anglice eodem fere argumento iustis voluminibus duobus docuit Civem bonum, aut moderatorem utilem esse posse Reip. neminem qui eius rationes cum vera Religione non coniungat; Ac deinde, Quae sit vera Religio: utraque multiplici auctoritate et solidis probationibus confirmans atque illustrans exemplis».

Especial aprecio gozó el Treatise concerning Policy and Religion. En 1615 se volvieron a editar ambas partes en Douai, en las prensas de John Heigham, impresor también en Saint-Omer, exiliado al igual que tantos ingleses. Nuevamente se reeditan ambas partes del Treatise en 1652; ya en Londres por el editor Abel Roper. En 1695, Thomas Hales saca a la luz la tercera edición revisada, también en Londres. Son cuatro tomos, en los que se han corregido errores de lengua y de

33 Traducción de la biografía del navarro, escrita en 1596 por Horacio Torselino.

34 Henry MORE, Historia ..., ver n. 9, p. 236. «Primero editó en latín una obra, docta y respetuosa, contra Maquiavelo sobre esta cuestión: ¿Hay utilidad en el mal? Después, en dos volúmenes, con prácticamente igual argumento, enseñó en inglés que nadie puede ser buen ciudadano ni gobernante de la sociedad, a menos que aúne su saber con la religión verdadera. Al final dice cuál es esta verdadera religión. Apoya ambas sobre múltiples autoridades y sólidas pruebas, y las ilustra con ejemplos». La traducción es nuestra. 
las anteriores impresiones. À Wood ${ }^{35}$ dice expresamente que esta edición fue tan bien acogida como las anteriores. Aunque Kippis en 1750 reconoce que la estima por estos tratados ya no es general, se leen poco y apenas se recuerdan. «These books of his, at the time they were published, were highly commended and much esteemed, though now they are little read, and hardly remembered $\gg^{36}$.

Nos hemos detenido con cierta amplitud en el recorrido biográfico y bibliográfico de nuestro autor porque ambos reflejan cómo en An sit utilitas in scelere fluye la misma vida de Fitzherbert. El contexto de la época y cómo él la vive manifiestan una integridad que permea todo el tratado. El fundamental tema de la virtus, tal y como Fitzherbert la expone, sólo se entiende como postura intelectual enraizada en la dignidad personal de ser creatura divina, pensamiento éste que Fitzherbert refleja cabalmente en su comportamiento, según reconocen los ya citados More, à Wood y Kippis.

\section{VIRTUS: IDENTIDAD DEL GOBERNANTE Y DE SUS ACCIONES}

\section{Contexto y objetivo conceptuales}

El contenido pedagógico es difícil diseccionarlo del filosófico, por ello el presente estudio tiene en cuenta los conceptos propios de la filosofía, teoría y pensamiento políticos, pero no profundiza en ellos: poder, origen del poder, consecución, legitimación y mantenimiento de éste; potestad divina, eclesiástica y civil; supremacía de la autoridad religiosa sobre la civil o viceversa; tipos de sociedad y formas de gobierno; cargas, oficios, impuestos, compensaciones a los ciudadanos y atributos, prerrogativas, privilegios de los gobernantes. Fitzherbert recurre a estos conceptos en la medida en que reflejan la dignidad del príncipe y la calidad de sus acciones (cc. 1 a 5$)^{37}$. Suponen siempre un apoyo técnico para la afirmación de la virtus y rechazo total del scelus. Absit! responde en numerosas ocasiones a las insidiosas objeciones de los maquiavelistas.

Lo mismo hace con la historia, a la que recurre en calidad de maestra, en la medida en que los príncipes virtuosos son modelo de imitación; los tiranos ejemplos para evitar. Deja espacio a reyes que, en medio de su falta de virtud, lograron

35 Anthony Á WOOD, Athenae..., ver n. 27, p. 538.

36 Edward KIPPIS, Biographia..., ver n. 20, p. 1941.

37 Entre paréntesis c. o cc. (capítulo o capítulos) y cifra arábiga. En arábigos también capítulo.número (no página) para el lugar de aparición de la referencia en An sit utilitas in scelere. 
sobreponerse y estar al frente de sociedades prósperas. Y al revés: gobernantes que se deslizaron hacia el mal arrastrados por la ambición y provocaron la ruina propia y de sus ciudadanos (cc. 11, 12 y 13).

Tampoco nos centramos en un aspecto que Fitzherbert trata con profusión: la justicia vindicativa. Se ocupa de este tema con el contrapeso determinante de la misericordia divina. La misericordia (en sus diversas expresiones: clemencia, paternidad, caridad) ha de relucir en el monarca como reflejo de la divina y ser él mismo causa de ejemplaridad para sus súbditos.

Cabe añadir que, en rigor, Fitzherbert no redacta un libro de regimine principum, o espejo de príncipes. Su finalidad educativa sobrepasa el consejo sobre la formación del carácter del gobernante, cualidades en las que ejercitarse o acciones que emprender o evitar.

Ciertamente filosofía, historia, consejos, enseñanzas y ejemplos se integran en An sit utilitas in scelere, y se reorientan hacia la fundamentación en la naturaleza de la virtus; y sobre ésta, la política, el político y la res publica. Por ello, esta obra constituye un tratado de pedagogía política, quizá único.

El tratado que presenta Fitzherbert, visto su objetivo principal, emana pues de una literatura académica antes que sapiencial; pero tampoco academicista. No nos hallamos ante una obra filosófica, ni de enseñanza moral ni de historia política. Estamos, lo repetimos, ante un tratado pedagógico. Además se ha de tener en cuenta la formación en leyes de nuestro autor, y en concreto su especial querencia por la ley natural. Hemos de conceder importancia al sustrato vital que refleja: los años en los que Fitzherbert se ha desempeñado en las cortes europeas para misiones diplomáticas han dejado su huella. En este último aspecto se acerca a Maquiavelo como escritor. Por último, el tratado se escribe en forma de debate y diálogo con Maquiavelo y sus seguidores. Y, en cierto modo, como en un juicio, tras la exposición de los fundamentos se presentan alegatos y objeciones, que Fitzherbert resuelve con las pruebas de la historia y las escrituras.

Todo esto repercute en el estilo formal que nuestro autor escoge. Fitzherbert no se atiene al género de los regimientos de príncipes, ni al de tratados de filosofía, ni al de crónicas históricas; tampoco redacta una controversia y menos una obra apologética, se ha dicho. Nuestro autor reúne y utiliza elementos de todos estos géneros, acentúa el nivel académico con profundidad de argumentación y lo reviste con un ropaje de diálogo para interpelar y provocar la reacción y reflexión. Por todo ello, se puede concluir, estamos ante un tratado único: un tratado de pedagogía política centrada en la virtus.

Por supuesto, Fitzherbert conoce la abundante literatura de príncipes, la filosofía e historia de su siglo, los escritos de asunto político, los autores antima- 
quiavelianos. Pero su base intelectual (Aristóteles, Agustín de Hipona y Tomás de Aquino) fluye en el cauce del derecho natural (sería de desear un estudio sobre su posible lectura de Francisco de Vitoria). Desde aquí se vierte en la pedagogía. El itinerario intelectual estaba bien marcado desde los años de su formación en Oxford y Londres.

Sí consta que sintoniza perfectamente con Pedro de Ribadeneyra, a quien alaba y cuya lectura recomienda en 4.14. La cercanía es obvia con sólo leer el título: Tratado de la religion y virtudes que deue tener el principe christiano, para gouernar y conseruar sus estados: contra lo que Nicolas Machiauelo y los politicos deste tiempo enseñan, de 1595. Con el jesuita español comparte también el problema patrio-religioso inglés: Historia ecclesiastica del Scisma del Reyno de Inglaterra, de 1588. Fitzherbert firma An sit utilitas in scelere contra las tesis de Il Principe de Maquiavelo, pero no es antimaquiaveliano como un Gentillet, personificación del escritor anti-mach, o un Tomás Bozio, éste último conocido de nuestro autor. Sydney Anglo concede a Fitzherbert una fuerza y valía intelectual por encima de sus oponentes y partidarios; aporta datos del sello propiamente inglés de la sensibilidad antimaquiaveliana, en la estela de escritos desde el tiempo del cardenal Reginald Pole ${ }^{38}$.

Establecido el marco de estudio, nos ceñimos al objetivo pedagógico que Fitzherbert se propone con este tratado de educación política (Prooemium): rebatir el scelus que Maquiavelo, en Il Principe, asienta sobre la razón de estado como última referencia. An sit utilitas in scelere hace emerger, a contrario, la virtus fundada en la ley natural, otorgada por Dios al hombre, en orden al desarrollo, perfección y consecución del fin de cada hombre, que coaligado en sociedad logra mejor que individualmente.

La literatura anti-mach como tal conoce autores y títulos en la Península ibérica con evidente retraso respecto a los territorios aludidos, al final del siglo XVI, tras la censura de Maquiavelo en el Índex Librorum Probibitorum de 1584. Salvo Ribadeneyra, ninguno de esos autores fue de calado como para dejar huella en el trabajo de Fitzherbert. Suárez y Mariana publican después de nuestro autor inglés, quien ya había escrito sus dos obras mayores. Además, éstas fueron gestadas, según menciona Fitzherbert en la Epístola Dedicatoria de An sit utilitas in scelere $(\$ \$ 3,4$ y 5$)$ en torno al cambio de siglo.

38 Ver Sydney ANGLO, Machiavelli. The First century, Oxford-New York, 2005, especialmente el capítulo 4, para entender las acusaciones por maquiavelistas contra políticos ingleses desde Cranmer bajo Enrique VIII. En las pp. 392-395, sobre Fitzherbert, otros antimaquivelistas europeos y sus posibles influencias entre ellos. 
Si hubiera que buscar alguna semejanza, se puede afirmar que nuestro autor inglés traza su línea expositiva sobre las huellas de Felipe de Comines, Francesco Guicciardini o el propio Maquiavelo, políticos que reflexionan sobre sus vivencias y las transmiten por escrito. Fitzherbert, evidentemente, con especial fuste filosófico y moral, y con marcado interés -con alma de educador- para que sirvan de enseñanza a su hijo y cualquier ciudadano consciente de su aportación a la comunidad política ${ }^{39}$.

Fitzherbert tampoco escapa al indudable espíritu humanista acuñado por los tres grandes de Europa: Erasmo, Moro y Vives, quienes beben de las mismas fuentes que nuestro autor ${ }^{40}$. Como él, denuncian con claridad los excesos de los tiranos, pero a la vez muestran un optimismo en la naturaleza humana que permite al hombre -también al político que fracasa- corregirse y elevarse ${ }^{41}$.

An sit utilitas in scelere no es encasillable entre los tratados de educación de príncipes al uso, aunque verse sobre contenidos propios de este tipo. Por supuesto, la perspectiva propiamente pedagógica la tienen en común. Pero Fitzherbert añade, ya se ha aludido, su fundamentación en la ley natural, con savia cristiana, y a la adopción de un ropaje académico y vivencial.

Fitzherbert confiesa que esta perspectiva basada en la ley natural le parece enormemente atractiva. La considera muy adecuada y decisiva para convencer con esta arma intelectual a quienes arruinan al hombre y a la sociedad, a los políticos de la nueva ola y al lector, quizá llevados a confusión (2.25).

39 En este sentido resultan muy esclarecedores: Allan H. GILBERT, Machiavelli's Prince and its Forerunners. The Prince as a Typical Book de Regimine Principum, Durham, 1938 ${ }^{1968 \mathrm{rp}}$ y Mario PRAZ, Machiavelli in Inghilterra, ed altri saggi, Roma, 1943.

40 Los tres escribieron a sus monarcas tratados de educación para los herederos al trono. Su influencia en suelo inglés, de interés por ser la patria de Thomas Fitzherbert, ha sido estudiada por Aysha Pollnitz en Princely Education in Early Modern Britain, Cambridge, 2015.

41 Hay que decir que el interés por Maquiavelo en España fue menor respecto a reinos como Francia, Inglaterra, o las repúblicas de la Península itálica. Los autores hispanos se ocuparon del florentino con menor urgencia; incluso algunos compartieron ciertos aspectos tácticos. Continúa siendo obra de referencia $M^{a}$ Ángeles GALINO CARRILlO, Los tratados sobre educación de príncipes (siglos XVI y XVII), Madrid, 1948; la autora se centra en autores de la Península ibérica, entre ellos los antimaquiavelistas. Datos más actuales autores hispanos se recogen en Forte Monge, Juan Manuel y López Álvarez, Pablo (eds.), Maquiavelo y España. Maquiavelismo y antimaquiavelismo en la cultura española de los siglos XVI y XVII, Madrid, 2008. Nosotros vemos coincidencias, y cierta deuda -más bien sintonía, como dijimos más arriba- con Pedro de Ribadeneyra. Sidney Anglo extiende, en algunos rasgos al menos, la cercanía de Fitzherbert con Jerónimo Osório da Fonseca, a través de Ribadeneyra, quien ha leído y parafraseado $D e$ nobilitate civile et christiana, publicada en 1543 por el portugués en Lisboa (op. cit. pp. 145, 391 y nota 26, 392). 


\section{El creador y la naturaleza referentes del hombre y de la virtus}

Sobre estas premisas (delimitación del campo de estudio y objetivos de Thomas Fitzherbert) exponemos a continuación los argumentos.

Desde la Atenas de Solón del siglo V, por ubicarnos en una sociedad desarrollada y en una fecha suficientemente documentada anterior al nacimiento de Cristo, la civilización que llamamos occidental se ha construido sobre unos principios políticos comúnmente aceptados.

En la vida política (una praxis y consecuentemente una ética) el pensamiento distingue dos ámbitos engarzados en la realidad, que se exigen mutuamente: la persona (gobernante: monarca, príncipe, rey, magistrado...) y sus acciones. Ámbitos que están en la base de la acción política, de la reflexión filosófica y de la doctrina pedagógica.

En la persona hemos de distinguir su identidad, motivación, objetivo y lo que a ella se le ofrece para realizarla: el poder o mando, el origen de éste, atributos y privilegios.

En las acciones a su vez necesitamos diferenciar: la acción misma, los medios y los modos al realizarla, la finalidad, las consecuencias.

Todos estos elementos integrados constituyen el marco moral de la política, el uso que ha ido regulando la vida de los hombres en sociedad, su relación entre sí y respecto a su rex-rector. Cada elemento y todos en conjunto cualifican la praxis política según una valoración ética.

La pregunta sería ahora ¿qué cualificación ha de aplicarse a la acción política para considerarla tal? Ha de ser buena y útil, porque se realiza según la virtus y se orienta a la utilitas $^{42}$ de la res publica.

En este punto se imponen nuevas preguntas ¿quién decide, de dónde emana, cuál es el referente de bondad y utilidad en el que contrastar la acción política? Cuestiones que convergen en una respuesta comúnmente aceptada: la naturaleza. Ésta constituye la piedra de toque, el referente anterior, superior y externo de la bondad y utilidad del quehacer político.

La vinculación de la persona con quien le ha dado sus leyes y la adecuación de su actuar a la naturaleza es la virtus ${ }^{43}$. En el príncipe, la virtus, ínsita en la naturaleza,

42 En el ámbito de lo social utilitas, utilidad, es sinónimo de bondad moral. Éste es el sentido que Fitzherbert otorga a esta palabra.

43 Con cita de Cicerón (De Finibus Bonorum et Malorum, 4.14) Fitzherbert indica que conviene al hombre vivir según la naturaleza: «honeste vivere, illud nihil esse aliud ait [Cicero], nisi naturae convenienter vivere» (1.1). La virtus hace lo conveniens, por tanto, et bonestum, añade Fitzherbert: 
es antecedente, exterior, le inviste de la dignidad de príncipe; lo configura para hacerlo apto en orden a su misión; de ella emanan sus acciones como causa eficiente ${ }^{44}$.

Fitzherbert se inserta en esta linea conceptual, en último término antropológica. Los títulos de An sit utilitas in scelere son suficientemente elocuentes de la primacía de la naturaleza: «Scelus, non minus principi quam reipublicae perniciosum: Item principem plus debere reipublica quam sibi lege naturae». [E] crimen no es menos pernicioso para el príncipe que para la república. A la vez, por ley natural, el príncipe se debe a la república antes que a sí mismo], (c. 2). «Qualem principem requirit natura; et quaedam de principis potestate, et officio». [Qué príncipe requiere la naturaleza y qué poder y obligaciones tiene el príncipe respecto a ésta], (c. 3). A tal punto apasiona a Fitzherbert la ley natural que querría que Dios le dé la ocasión para escribir un libro sólo sobre ella. Con humor, dice que hasta sus adversarios malinterpretarían esta fascinación, como si con ello derogase la dignidad y potestad de la ley eclesiástica (c. 5$)^{45}$.

Con el capítulo quinto concluye la primera parte de An sit utilitas in scelere. «De lo anterior se concluye contra Maquiavelo que su príncipe es lo más alejado a la naturaleza y no menos su propia ruina y la de la república». Fitzherbert ha demostrado que la dignidad del príncipe y de la verdadera política que él lleva a cabo descansan sobre la naturaleza y la virtus. A partir del capítulo 6 la fundamentación filosófica deja espacio a un desarrollo más técnico de las acciones políticas del príncipe, así como a mostrar los ejemplos históricos de príncipes o tiranos, y a alertar a los políticos sceleratos de la implacable justicia divina ante la virtus despreciada.

«nihil enim naturae consentaneum esse potest, quod non ídem honestum sit, nec honestum aliquid quod cum natura pugnet». (1.1). El concepto utilitas se enmarca en el fin de la naturaleza, que tiende a lo bueno y lo conveniente, que es conservarse, desarrollarse y sobreexistir. Para ello se sirve de lo útil = utilitas. Así, rechaza lo malo, inconveniente, lo no-útil = scelus, que impide y frena desarrollar su potencial. La inutilidad, el scelus, violenta, viola y vicia la naturaleza, conduce a la ruina, perversión, depravación, degradación o monstruosidad.

44 Fitzherbert utiliza pues el concepto virtus exclusivamente en este sentido. Lo cual no impide que, a la hora de describir qué características ha de poseer el príncipe, llame virtudes a sus actos de prudencia, magnanimidad, piedad, justicia, clemencia, generosidad, caridad: hábitos en su acción que a la vez le perfeccionan en su dignidad.

45 «Theologi, sed antiqui etiam philosophi tradiderunt, ut alio opere, si deo placuerit, planissimum faciam, hic enim haec tetigisse sufficiet, nedum políticos ad naturam provocem de ecclesiastica videar aliquid derogare dignitate et potestate, quam divina lege tum constitutam, tum omni humanae potestati praelatam esse, ex sacris litteris satis liquet». (2.25). [Baste por ahora lo ya tratado, no sea que provoque la sensibilidad de los políticos o parezca que me arrogo algo de dignidad y potestad eclesiástica. Que ésta se fundamenta en la ley divina y antecede a toda potestad humana queda suficientemente claro a partir de las Sagradas Escrituras]. En el relato autobiográfico hemos visto cómo la naturaleza creada inflama su amor a Dios. 


\section{La virtus: circunscripción de su significado}

Una vez que se ha explicado el referente del príncipe en la naturaleza y en su creador, es oportuno aclarar qué contenido expresa Fitzherbert con la palabra virtus. Se atiene nuestro autor a la doctrina que parte desde Aristóteles y culmina con el Aquinate. Nos servimos del jesuita Iván Eusebio de Nieremberg que la clarifica en su escrito Obras y días. Manual de Señores y Principes ${ }^{46}$. Recurrimos a este autor porque comparte con Fitzherbert unidad de doctrina y currículo de estudios propio de los jesuitas: Ratio atque Institutio Studiorum Societatis Iesu. Habitualmente conocido en su forma breve, Ratio Studiorum, este plan de estudios tiene fecha de 1598, aunque el año de la publicación oficial fue 1599. La Ratio se definió bajo el generalato de Claudio Acquaviva, con quien Fitzherbert mantuvo las conversaciones de solicitud para formar parte de la Compañía.

$\mathrm{El}$ autor aclara las tres acepciones de la palabra virtud, para iniciar la explicación de lo que se entiende por virtud en lo que tienen en común y en la integración de sus particularidades ${ }^{47}$ :

Es pues la Virtud un asseo, y esfuerço del alma; para ajustarse a la razón en si, y en sus obras. Pero conforme a la definición que trae santo Thomas, sacada de algunos lugares de san Agustin: Es una buena qualidad del alma, con la qual se vive rectamente, de la qual nadie usa mal, la qual Dios obra en nosotros sin nosotros. Esta difínicion en la forma que declararemos, es general, que abraça todas las Vitudes, y muestra mucho sus ventajas. Otra se puede recoger de otras sentencias de Aristoteles, que es esta. La Virtud es un habito para eligir lo que es bueno, por el qual el hombre que le tiene se haze bueno, y haze buenas sus obras. $\mathrm{Y}$ aunque Aristoteles no quiso abarçar todas las Virtudes, sino las Morales no dexará de aprovechar esta definición para explicar en parte la naturaleza de la Virtud en comun.

Se ocupa Nieremberg ahora de la acepción general y despliega su contenido en relación con el concepto de virtud como hábito fruto de la repetición de actos:

Dizese lo primero, ser la Virtud una Qualidad del alma: porque no consiste en las mismas potencias naturales, sino en una habilidad y disposicion permanente, que fortifica las potencias, y un adorno que la assea y compone. No son Virtud el

46 Publicado en 1629 en Madrid por la viuda de Alfonso Martín. El autor fue un reconocido, prolífico y polifacético erudito, hijo de padres germanos, que se instalaron en Madrid con la Corte de Carlos V. Los siguientes párrafos se entresacan del capítulo 2, De la naturaleza de la Virtud, pp. $4 \mathrm{v}$ a $13 \mathrm{v}$.

47 Reproducimos los pasajes respetando la grafía del original. Se adaptan a la grafía de uso actual: v y b; f y s. Se respeta ç y el uso de mayúsculas. Se resuelven signos de abreviación: q en que; nasal $\mathrm{m}$ o $\mathrm{n}$ ante otra consonante, señalada con vocal bajo tilde recta. 
Entendimiento, la Memoria, ni Voluntad; sino aquella fuerça sin forçar, o habito, que blandamente las inclina, mueve, y perficiona. Con aver sido criado el hombre para el mas alto y arduo fin, que es la conquista del cielo, y bienauenturança, sale al coso y palenque de la vida el mas flaco, y desarmado de todos los animales. Nace desnudo, no solo en el cuerpo, sino en el alma; y en esta mucho mas: porque no solo nace desarmado, y desnudo, sino despojado de la gracia, debilitadas y tronchadas las fuerças de la naturaleza misma viciada con el pecado. Y sino fuera ayudado del fauor divino, y esforçado y guarnecido con la Virtud, no pudiera, no digo conseguir, pero ni proseguir, ni mirar a su fin en orden, al qual tiene feliz facultad con la Gracia, y con la Virtud, deuda de la misma Gracia, por lo menos facilidad.

Llámase esta qualidad con titulo privilegiado, Buena. Porque es principio de la bondad de las obras, y de las personas que la tienen. (...) Assimismo la Virtud perficiona a quien la tiene y haze que saque sus obras perfetas y esmeradas.

Unas líneas más adelante explica la virtud en relación con el hábito:

Esta qualidad tan hermosa y tan extremadamente buena, que haze solamente buenos, es habito, que dize permanencia; si quiera porque ni en durar se la aventajen los males. S. Gregorio Nazianzeno la llama habito de las cosas hermosas. Habito es, porque en qualquiera especie de Virtud no basta un acto particular para que sea un hombre virtuoso: costumbre es menester nacida de muchas acciones. Fue esta saludable traça de la naturaleza, y consejo divino: porque lo bueno justo es se repita muchas vezes. La facilidad, que por esta costumbre se gana se llama habito porque dispone y habilita al que la tiene para la ejecución de la obra virtuosa. (...) Esto es en quanto a las Virtudes naturales.

A este marco conceptual hay que añadir que el ejercicio de la virtus presupone un aprendizaje; la persona, que es libre, no funciona por automatismo. El príncipe ha de actualizar, fortalecer, dar vigor a sus cualidades para cumplir su misión; ha de cultivar el conocimiento de la materia y resortes del gobierno; ha de encaminar sus actos en servicio de la sociedad y sus integrantes. Fitzherbert, con la tradición, llama a este gobernante príncipe óptimo.

Se engarzan pues los enfoques de la virtus como cualidad recibida configuradora de la dignidad de la persona que la sustenta y como cualidad perfeccionadora por medio de sus acciones. Por ello Fitzherbert insite en la necesidad que tienen los gobernantes de educarse: discant, legant, animadvertant. Que aprendan a conocer su misión: servir a la república; que aprendan cómo servir; que aprendan qué acciones han de emprender. Todo este aprendizaje constituye la palestra en el que se ejercitan en las virtudes concretas (prudencia, piedad, justicia, mesura...), y se refleja en la dignidad, en el ejercicio de gobierno y en la mejora personal. Así, fama y gloria no son sino fruto natural de lo que no se persigue por sí. 


\section{LÍA VIGURIA GUERENDIÁIN}

La realidad que Fitzherbert ha vivido en su patria y que todavía perdura se encuentra en las antípodas de estos ideales. $\mathrm{Al}$ escribir An sit utilitas in scelere, Fitzherbert dice que la motivación que le conduce a querer derribar a Maquiavelo y sus tesis es el pensamiento de su lejana patria, envuelta en lamentables sucesos ${ }^{48}$. La biografía pesa sobre el autor, que ha visto cómo las familias de la old religion -objeto de presión y persecución- ven mermadas sus fortunas y su libertad de movimientos; por el contrario, aumenta la regresión social de los católicos. La familia Fitzherbert es un ejemplo clarísimo de esta persecución, sibilina en sus comienzos, y descaradamente pública desde 1580. Al final del reinado de Isabel I, su aparato de poder ya había conseguido eliminar de la vida pública a los católicos. Si no era la anglicana, religión era igual a traición ${ }^{49}$. Así, puede considerarse perfecto político secuaz de Maquiavelo a uno de los persecutores de los Fitzherbert, Richard Topcliffe ${ }^{50}$.

Fitzherbert es testigo de cómo la razón de estado maquiaveliana ha suplantado a la virtus y se ha convertido en la habitual referencia, al menos entre algunos jueces, que la van infiltrado en la administración de justicia ${ }^{51}$. Refiere él mismo esta

48 Epistola Dedicatoria 1 a 7.

$49 \ll$ «nlike her half sister Mary, who killed Protestants for their religious beliefs, Elizabeht made every effort to identify her victims as traitors rarther than heretics». Carlos M. N. EIRE, Reformations: The Early Modern World, 1450-1650, New Haven and London, 2016.

50 John Hungerford PoLlen, Unpublished Documents Relating to the English Martyrs, vol. 1: 15841603, Catholic Record Society Record Series, t. 5, 1908, London, pp. 363. «The persecution of the Fitzherberts: Topcliffe seems to have been relegated to obscurity, and then allowed to retire to the country, and to enjoy the estates and the other spoils which he had and the other spoils which he had acquired from his many victims. Topclitfe's name does not appear again (so far as I can see) in the annals of the persecution, and six years later he was lying dead at Padley in Derbyshire, the house of the Fitzherberts, where the martyr Garlick had been captured through his means. (See Dic. Nat. Biog., lvii, 52; Jessopp, One Generation of a Norfolk House, p. 64; Harleian MSS. 6998, n. 50.)». Topcliffe obtuvo la traición de un Fitzherbert, primo de nuestro autor. Delató a su propio padre y a un tío paterno. El botín que obtuvo el policía fue quedarse con ciertas propiedades de la familia Fitzherbert tras extorsionar al propio traidor. A juzgar por la noticia de Pollen, Topcliffe finalizó sus días ignorado y relegado, casi como un desterrado.

51 Maquiavelo utiliza un concepto de virtus que él ha devaluado, desvirtuado, desnaturalizado. En ningún momento corresponde al significado que desarrolla y explica Nieremberg, es decir, el de la tradición y, con ésta, Fitzherbert. El florentino utiliza el vocablo italiano virtù, que en su época, junto al contenido moral, primera acepción, incluye la cercana a destreza; en castellano los vocablos virtuosidad, virtuosismo y virtuoso parten de esta acepción. Cercano a este significado, virtù conoce en Maquiavelo la acepción pericia. Así entendida, virtù permite acceder al poder en modo opuesto al que lo hace Fortuna. En nuestra opinión, aquí se produce el reduccionismo y el vaciado de significado. Agostino Nifo en 1523 así titula su versión latina (o plagio) de Il Principe: Augustini Niphi Medice Philosophi Suessani de Regnandi Peritia Ad Carolum. Con las traducciones de Il Principe a las diferentes lenguas el problema del significado ha ido aumentado. Junto a es- 
experiencia de vida en su área de dedicación liberal: las leyes. Aludimos al juicio, condena y ejecución de Campion. Gracias a este suceso, que supuso una conmoción en Londres, nos ha quedado un bello testimonio de sus relaciones de amistad, también con los anglicanos. Relata la reacción de un buen amigo protestante, jurista como él, que quedó sorprendido por la pena de muerte de Campion ${ }^{52}$ :

A gentleman of good account, a lawyer, and an earnest Protestant, yet a friend of mine, who was present at the arraignment, told me the day after, that in truth the evidences that were given against Father Campion were so weak, and his answers so sufficient and clear, that he could not persuade himself that he should be condemned, until he heard the chief Judge give the sentence of death. And when I asked him how it could stand with conscience to condemn innocent men, he answered that it was necessary for the State. And the like I heard credibly reported of another of the judges, who being asked afterwards by a familiar friend of his, with what conscience he could condemn Campion and the rest upon that evidence, he answered that he could do no less, for otherwise he should not be taken for a friend to Caesar.

\section{Crisis y declive del hombre vinculado a Dios}

La síntesis expuesta más arriba sobre el príncipe óptimo se ha hecho deliberadamente de modo aséptico y extemporáneo. Hemos evitado utilizar los términos bueno-malo. Al igual que hemos evitado entrar en la reflexión desde las

tas precisiones lingüísticas, existe toda una literatura académica sobre el contenido moral de la virtud en Maquiavelo, que resulta inabordable para referirla en el presente trabajo, pues nuestro objetivo es profundizar en la virtus tal como la expone Fitzherbert. Nos limitamos a hacer ver cómo Maquiavelo hace del mal virtud (utilitas in scelere); ésta se identifica con lo técnicamente útil al gobernante para mantenerse en el poder. La moralidad queda exenta de su horizonte de acción. En este sentido, virtud en Maquiavelo equivale a su concepto de razón de estado. Bien lejos de la virtus que en Fitzherbert inspira la recta razón de estado.

Para el término italiano virtù, tras la significación moral, ver la segunda acepción s.v. Virtù y ejemplos. «Per valore, eccellenza di buona qualità. Lat. virtus, prestantia. Bocc. n. 84. 2. Se egli non fosse più che malagevole agli huomini il mostrare altrui il senno, e la virtù loro. E g. 2. f. 2. La nostra virtù, e degli altri miei sudditi, farà sì, ec. Petr. Son. 203. Voi con quel cuor, che di sì chiaro ingegno, Di sì alta virtute Il Mondo alluma. E Son. 211. Ma il Mondo cieco, che virtù non cura». Accademici della Crusca, 1612, Vocabolario degli Accademici della Crusca, con tre indici delle voci, locuzioni, e prouerbi latini, e greci, posti per entro l'opera. Con priuilegio del sommo pontefice, del re cattolico, della serenissima Repubblica di Venezia, e degli altri principi, e potentati d'Italia, e fuor d'Italia, della maestà cesarea, del re cristianissimo, e del sereniss. arciduca Alberto, Venezia, appresso Giouanni Alberti, p. 941.

52 John Hungerford Pollen, Acts..., ver n. 12, pp. 38-39. 
Escrituras y la teología. El itinerario cultural de lo comúnmente aceptado no ha sido monolítico, ni ha estado exento de dificultades de interpretación. Las sensibilidades y creencias religiosas han influido en los conceptos y perspectivas. Cada etapa de la historia y de quien detentaba la hegemonía imprimía su carácter. Pero se había llegado a un marco conceptual político que fue compartido (en medio de contrastes, claudicaciones e incluso aberraciones) durante siglos: Dios y la naturaleza son los referentes incuestionados del hombre y de la vida política.

El acervo cultural de esta reflexión y praxis política que se ha ido consolidando durante veinte siglos en suelo europeo conoce un momento inicial de abandono y un precursor: en 1513 Nicolás de Maquiavelo escribe Il Principe. Es el primer autor en poner por escrito las bases que van a subvertir los cimientos griegos, judíos, romanos, cristianos y paganos que han mantenido una visión antropológica basada en la naturaleza, ciertamente redimensionada desde hace casi mil quinientos años por la savia cristiana: las Escrituras Sagradas, la reflexión de los padres de la Iglesia, y la vida política que ha ido configurando -mal que bienla cristiandad.

Obviamente existen antecedentes. Los propios hechos históricos hablan por sí: por toda Europa pululan príncipes, eclesiásticos, potentados... que han dejado de ser nobles para convertirse en déspotas y caprichosos tiranos. Las guerras asolan todas las regiones. Los peligros exteriores (el turco) ponen a prueba la unidad y suscitan infidelidades contra los socios naturales: la cristiandad se resquebraja. Esta situación afecta -como no puede ser de otro modo- a los intelectuales. En pleno apogeo humanista tanta dificultad se siente como un caos. Se pierde la sensación de estabilidad y los referentes habituales se abandonan. Atraen lo nuevo y lo antiguo; las religiones de pueblos desconocidos hasta el momento o la magia, el esoterismo o el recuerdo de los cultos precristianos, las ideas heréticas constituyen motivos atrayentes y suficientes para dejar lo católico.

Entre todo ello, emerge una nueva religión. Si el referente personal y social han sido Jesucristo y el Dios cristiano, el hombre que ve tambalearse lo que con Él se ha construido, queda decepcionado. Además, los pecados, males, escándalos que provocan hombres que debieran mostrar el rostro de Dios, alimentan el deseo de distanciarse de lo que ellos representan. Pero los sustitutivos, sufragáneos y sucedáneos tampoco convencen. Así, que todos los recientes logros de la humanidad hacen sentir al hombre que él es capaz de crearse a sí mismo, se cree autónomo, se desgaja del referente que le sujeta y frena, y se emancipa e independiza. Es un hombre que puede construirse ut si Deus non daretur, prescindiendo de Dios. El cordón umbilical se corta por lo sano. Perdido Dios, se pierde la naturaleza, se pierde la virtus. 
En el nuevo horizonte de la vida civil, Maquiavelo propone a un hombre político que se dota a sí mismo el referente, clave de éxito en sus acciones: lo llama razón de estado. Una vez que este hombre llega al poder se instala en su posición. Su obligada misión (se debe a sí mismo y no a la república) consiste en mantenerse en el poder a costa de la república y de los ciudadanos si es preciso. Su finalidad es el poder por sí mismo, justificada en la razón de estado. Todas sus acciones, instrumentos y modos encuentran en la razón de estado la causa eficiente; en último término, el propio príncipe. Dios y la virtus han desaparecido y con ellos todo horizonte y límite moral. Es un tirano al que Maquiavelo denomina príncipe. Resulta inútil hablar de aprendizaje. No hay sino interés y provecho en la meta de este gobernante, que creyéndose independiente, está a merced constante de los vientos de la Fortuna, alejado de la serena Providencia. Su instrucción se limita a leer las cambiantes circunstancias para manejarlas con habilidad y sustraerse a posibles peligros, en lugar de aplicarse a criterios de dirección con los que encaminarlas a la finalidad común.

\section{CONCLUSIÓN}

Nos hallamos pues ante dos figuras antitéticas, que se oponen intelectualmente. Por supuesto, sus posturas han coexistido a lo largo de toda la historia. Tras el largamente indiscutido príncipe óptimo, se alza el tirano hábil en el uso de mañas y artes, que ahora se enseñan para la consecución de la razón de estado. Es un gestor, antes que príncipe o político, quien irrumpe con Maquiavelo. Sus seguidores se encargarán de elaborar una construcción intelectual que haga justificable tal figura.

Lo que se ha expuesto en este trabajo puede presentarse en un esquema de doble contenido. Primero, el de la milenaria tradición que sigue un referente externo.

Persona: príncipe bueno (educatio en la ley divina y la naturaleza, según la virtus)

- decide bien

- actúa bien

- elige acciones buenas

- se sirve de instrumentos buenos

Acción: encaminada a cumplir bien su misión (instructio)

- mira el bien común de la república

- procura el bien particular de cada ciudadano

- resulta en la felicitas de la república

- repercute en su mejora personal 
Un príncipe bueno, a quien defina la virtus, cumple bien su misión -es apto - sirve para ser príncipe- es útil para estar al frente de la república. Su persona y acciones redundan en la utilitas de la república.

El nuevo marco conceptual del político y política autorreferenciales presenta un esquema paralelo. Diametralmente opuesto al precedente, sin punto de contacto ni posible convergencia:

Persona: tirano = el príncipe de la razón de estado (exercitatio en estrategia)

- decide en función de su provecho

- actúa movido por un afán pragmático

- elige acciones encaminadas a mantenerse en el poder

- se sirve de instrumentos utilitaristas

Acciones: encaminadas al éxito de la razón de estado (exercitatio en habilidades)

- mira su interés que la república debe servir

- extiende el miedo entre los ciudadanos

- convierte la república en tiranía

- repercute en su ruina personal

El príncipe facineroso es el tirano investido de la razón de estado. Sus acciones no tienen más fin que el de perpetuarse en el poder al que ha llegado per fas vel nefas. La república ha de estar sometida a la razón de estado que él se arroga. El sitema de gobierno que instaura es la tiranía. Este gobernante es el menos apto para la república, pues la conduce a la ruina, el más inútil. Fitzherbert no duda en calificarlo de scelerosus, sceleratissimus, nefandus, monstruosus, inhumanus. Estamos ciertamente en las antípodas del príncipe óptimo ${ }^{53}$.

Fitzherbert se ha propuesto que el tirano no silencie ni aniquile al príncipe. De hecho no lo desbanca. Sí presencia el avance del peligro en su Inglaterra natal, personificado en figuras como Thomas Cranmer, Francis Walsingham, Robert Cecil, Richard Topcliffe... nueva raza de políticos que responden al nuevo potentado. Comienza una coexistencia nada pacífica, que, en lo intelectual abre dos líneas de pensamiento político divergentes. Con el tiempo, la línea maquiaveliana autorreferencial se abre paso y desemboca en tristes sucesos en diversos reinos europeos hasta la propia Revolución francesa, y después, con variantes y

53 Resulta significativo que Maquiavelo considere a César Borgia su príncipe ideal, aunque al final la fortuna se le volviera en contra. Julio II es un político de éxito, que aprovecha sin dilación la oportunidad en cuanto se presenta. Maquiavelo admira a Fernando el Católico, teóricamente un ejemplo de príncipe, pero de hecho le desagrada por sus campañas victoriosas en Italia, que Maquiavelo vive como derrotas personales. 
reformulaciones hasta la actualidad... Mientras que la línea del príncipe de Dios y la naturaleza se ve obligada a reformularse, despojarse de elementos religiosos superfluos..., proceso de supervivencia que todavía hoy presenciamos.

Desde Il Principe conviven en Europa hasta hoy la cara y cruz del quehacer del gobernante y sus consecuencias. Discurren, pues, dos líneas de pensamiento y reflexión filosófico-pedagógicas divergentes en progresivo distanciamiento. Una continúa la multisecular tradición de respeto al referente en Dios y la naturaleza. En ésta se encuentra claramente Thomas Fitzherbert, en el surco de Moro, Erasmo, Vives, Francisco de Vitoria, los autores de la escuela de Salamanca, Bellarmino, Possevino, Mariana, Suárez. La nueva línea iniciada con Maquiavelo reúne a Bodino, Francis Bacon, Calvino, Zwinglio, Teodoro de Beza ${ }^{54}$.

No es fácil desgajarse completamente de la herencia ni ignorar los nuevos vientos. Por ello, junto a estas posturas en claro desencuentro, algunos autores, sin pretender un sincretismo declarado, aprovechan elementos de una y otra vertiente: Botero, Lipsius, Hugo Grocio.

Thomas Fitzherbert detesta este nuevo orden de cosas. Pero lejos de quejarse y no contribuir, sale con las armas que puede blandir: la pluma y la razón. Su ánimo es combativo, no se arredra ante sus limitaciones para la lucha, ni ante posibles enemigos. Merece la pena batirse por la virtus, por la referencia del hombre a Dios y por la paz política.

Fitzherbert traduce su fundamentación filosófica y antropológica, anclada en el cristianismo humanista, en un itinerario pedagógico para cualquier estadista. En el palenque de la vida política, el gobernante necesita aprender la virtus para ejercer el imperium inherente a su misión. Pero a la vez, la virtus es presupuesto del cual goza el príncipe y subviene a la tarea: conducir a cada persona integrante de la sociedad y a ésta en su conjunto hacia su bien y felicidad. Es más: ejercer este servicio según la virtus engrandece al gobernante, quien se hace valer, se convierte en príncipe útil, óptimo. Con el éxito en su officium-ministerium -actuando según la ley divina y la ley de la naturaleza- todo gobernante alcanza

54 Algunos autores mencionan a los humanistas Marsilio Ficino (1433-1499) y a Felipe de Comines (1419-1467) entre sus predecesores; si bien comparten algunos rasgos, estos dos autores no se apartan de la referencia a Dios y a la naturaleza, que el florentino llevaría a su máximo desarrollo. Algunos autores actuales incluyen en esta línea maquiaveliana a Francesco Guicciardini (1483-1540). Thomas Fitzherbert lo cita, también a Comines, en An sit utilitas in scelere. En absoluto lo haría si entreviera en ellos el menor atisbo de doctrina maquiaveliana. Aunque no ha sido objeto de este trabajo, ambos humanistas defienden la Providencia divina, tema clave que les separa del pesimismo ante la Fortuna que sujeta a Maquiavelo. 
además el propio: mantenerse al frente de su pueblo, lograr la gloria y el amor de sus ciudadanos, reflejar la imagen de Dios.

La virtus constituye pues la cualidad esencial que distingue a todo gobernante. Es la única característica de sus acciones que le asegura lograr el éxito en su misión política. En definitiva, la virtus es lo único útil para el estado, sus integrantes y su moderator.

\section{ANEXO}

\section{Autobiografía interior}

El texto que sigue es la traducción del que incluye Henry More en su obra sobre los jesuitas de Inglaterra. Ver nota 9. Este biógrafo engarza tres autógrafos de Fitzherbert a partir de un escrito de conciencia que le solicitan que reproducimos como aparecen en el volumen de More.

Para nuestra transcripción: el autógrafo más largo y principal no va entre comillas. Fitzherbert incluye dentro de éste una cita a un documento de su mano; éste sí va entre comillas. El tercer texto de la mano de Fitzherbert, introducido por More, también se pone entre comillas.

En cursiva reproducimos las breves palabras de More.

La traducción es nuestra. Se ha reflejado el tono de época y autor del original, en la medida en que resulta legible al lector de hoy.

Yo, Thomas Fitzherbert, a la de edad de sesenta y dos años, inglés, hijo de William Fitzherbert y Elizabeth Swynnerton, por santa obediencia voy a responder a las preguntas que se me han propuesto relacionadas con mi vocación a la Compañía de Jesús.

Primero, en lo relativo a devociones particulares, omitiendo las habituales, por gracia de Dios siempre cultivé una especial devoción a la Santísima Virgen: Ya cuando tenía unos veinte años rezaba su oficio a diario, al que añadí otras obligaciones. Ayunaba en todas sus vigilias y además me abstenía de huevos, pescado y cualquier lácteo. Rezaba todos los días una corona, dos los sábados. Me confesaba y comulgaba, rezaba un rosario completo en sus fiestas o en la octava, y siempre que estaba en casa los sábados ayunaba.

En el año ochenta y ocho (ya fallecida mi esposa) después de hacer Confesión general con cierto Padre de la Sociedad, en la Fiesta de la Anunciación, hice voto de Castidad en honor a la Virgen. Y en mil seiscientos uno, estando en España, en la Fiesta de su Natividad prometí iniciarme en el Sacerdocio, pues podía ofrecer 
un regalo aún mayor a Dios y a su Santísima Madre. Así, el año siguiente, en la Fiesta de la Purificación, aquí, en Roma, vestí el hábito sacerdotal; recibí el Sacerdocio la víspera de su Anunciación el mismo año, y canté mi primera Misa en la propia Fiesta. Prometí también leer a diario el oficio de Spiritu Sancto, y otras oraciones en honor de la Santísima Trinidad y de los patronos; también ayunar los miércoles y viernes cuando me fuera posible.

A la religión en general me movía la consideración de que todos los cristianos deben atenerse a perfecta abnegación, y como a ella se llega mucho más fácilmente en el estado religioso que en el secular, decidí abrazar ese estado. En concreto, me parecía que el Instituto, que tiene como fin propio propagar la fe católica y la salvación del prójimo, en este tiempo era más necesario y útil a la Iglesia de Dios, pues precisamente une la vida activa con la contemplativa a la perfección; y éste sería antes que cualquier otro el más idóneo para la conversión de Inglaterra. Así, en el año mil seiscientos, en Santa María la Mayor, y en la fiesta de la Asunción de la gloriosísima Virgen, prometí vivir y morir en la Compañía de Jesús, siempre que el Reverendo Padre General Claudio Acquaviva se dignara admitirme. Esta es la copia de ese voto:

«Ayudado con la gracia de Dios y el auxilio del Espíritu Santo, por los méritos de la Pasión de Nuestro Salvador Jesucristo y de la intercesión de la Santísima Virgen María, de mi santo Ángel Custodio, de San Ignacio y de todos los Santos, prometo y hago voto ante Dios Omnipotente, humildemente y con todas mis fuerzas, de que he de solicitar al Reverendísimo Padre General de la Compañía de Jesús se digne admitirme en esta Sociedad. Que en el momento en que le parezca oportuno que yo acceda a realizar la probación, al instante ingresaré en el noviciado y tomaré el hábito de la Sociedad; y en consecuencia me atendré a sus reglas e instituciones mientras viva. Entre tanto, prometo y hago voto de que me someteré a la autoridad de su reverendísima paternidad y la de todos aquellos a los que encargue de mi cura y régimen; igualmente a cualquier otro Padre General y Superior de la misma Sociedad. Así ha de entenderse: que ahora renuncio enteramente a mi voluntad, incluso a la de entregarme total y para siempre, y que me someto al actual Reverendísimo Padre General y a los sucesivos Generales de la Compañía de Jesús hasta que muera. En testimonio de lo cual escribo el presente de mi propia mano y firmo en Roma el 15 de agosto, en la fiesta de la Asunción de la Santísima Virgen María de 1606. Thomas Fitzherbert».

En la fiesta de su natalicio me recibió él mismo en su cámara para el almuerzo, estando presente el Padre Persons. Se estimó con todo que sería más útil para la gloria de Dios y como deferencia de la Sociedad que no fuera al Noviciado ni cambiara de hábito durante algún tiempo; se me dio como Superior al Padre Thomas Owen, en aquel tiempo Ministro del Seminario de los Ingleses. Más tarde, ante él emití los tres votos de la Sociedad. Después hice ante todos profesión pública de mi empeño en aplicarme a observar cuanto pudiera todas las reglas de la Sociedad fuera de sus colegios y casas: como los tiempos de oración, de exámenes, de lectura, de renovación, de dar cuentas de conciencia; que cada mes leería las reglas y mostraría a mi superior todas las cartas que yo mismo escribía 


\section{LÍA VIGURIA GUERENDIÁIN}

y las que recibía, que sin su licencia particular o general no gastaría un penique: todo lo cual puede testimoniar el mismo Padre, que ya ahora es Rector de ese Seminario.

Sobre las gracias, también particulares, he de responder: reconozco que, a mí, indignísimo y muy grave pecador, la divina bondad me ha comunicado varias; a mí, que nada merecería sino el Infierno. En primer lugar, aun habiendo nacido en el reinado de un rey herético, Eduardo Sexto, el año mil quinientos cincuenta y dos -cuando en Inglaterra no había pública profesión de la religión católica- por especial providencia y misericordia de Dios, mis padres, los dos, eran católicos, y fui bautizado según el rito completo de la Santa Iglesia. Fui también educado según la fe católica.

Recuerdo también que cuando era niño de unos cinco o seis años ya gozaba de la luz y el don de la fe. Solía quedarme mirando al cielo y pensar sobre Dios, especialmente en su eternidad y en su existencia desde siempre sin principio, y me empeñaba en entender cómo podía ser esto; pero a pesar de no captarlo, creía en ello lleno de admiración. Me parece que tenía también una fe expresa en la Resurrección, si bien envuelta en un concepto infantil; pues en el año mil quinientos cincuenta y ocho, tenía seis años, murió el primero de mis padres, y cuando uno de mis familiares me lo dijo, esperó a ver qué respondía, pues me había quedado un rato callado y en duda, como quien medita algo. Cuando se dio cuenta, me preguntó en qué pensaba y le respondí que lo que me dolía de la muerte de mi padre era que cuando resucitase en el día del Juicio aparecería corroído por los gusanos y lleno de agujeros. Tiempo después, ése mismo, ya amigo, me lo volvió a recordar: y creo que la memoria de esta respuesta me quedó grabada para siempre.

Dios sembró además desde la misma infancia la semilla de otras virtudes, aunque, por mi falta de razón y muy mal carácter, no produjeron el fruto debido. Cuando llegué a la edad de los nueve o diez años, me arrebató un gran deseo de hacer limosnas, y como no tenía con qué hacerlas, guardaba alimentos de casa que cogía a escondidas y luego iba a distribuirlos a los pobres; ayunaba, aunque con cierto desorden, pues no tenía un padre espiritual que me dirigiera. Cuando tenía no más de doce años, me dicté a mí mismo un ayuno de sólo pan y alguna fruta los tres últimos días de Cuaresma. Como me había ido enterando de muchas cosas de los Padres de la Sociedad y de su instituto, me encariñé enormemente con ellos y con todo a lo que ellos se dedicaban. En esa época me cautivó un gran deseo de martirio y a menudo rogaba a Dios que me hiciera esa gracia.

Con la edad, crecía en mí la luz de la fe y -por la infinita bondad de Dios-aumentaba mi celo por la fe católica y mi odio a la herejía; tampoco me gustaba tratarme con herejes ni acudir a sus reuniones. Sobre este asunto no puedo omitir un regalo que Dios me hizo. Cuando era un joven de dieciséis años y estudiaba en la universidad de Oxford, por curiosidad me asaltó la tentación de acudir a una reunión herética. Con todo, no quise hacerlo sin pedir consejo y acuerdo a quien entonces era mi habitual confesor. (Era éste un sacerdote no muy docto, 
que se escondía en Oxford por la persecución). Le pedí su parecer y me respondió que podía participar sin pecar si iba, no con el ánimo de aprender, sino sólo de asistir. (Lógicamente, en aquellos tiempos poquísimos católicos se ausentaban de las reuniones, aunque no quisieran participar en las oraciones). Así que, una vez recibido el parecer de mi confesor, salí un día para escuchar a cierto predicador famoso. Antes de llegar yo, él ya había subido al púlpito; pero en cuanto puse un pie en el templo me invadió tan vehemente horror que no pude de ninguna manera permanecer allí. Así que salí como el rayo sin haber oído otra palabra que el nombre de Jesucristo. Desde aquel momento he dicho abiertamente a todos que soy católico; y donde quiera que iba defendía la religión católica contra ministros u otros herejes y confortaba a los católicos. Por ello estuve casi dos años obligado a esconderme hasta que me cogieron y me metieron en la cárcel, con gran regocijo para mí. Después de ese tiempo, vinieron a Inglaterra los Padres Campion y Persons, me uní a ellos y les servía del modo que podía; hasta que, al aumentar la persecución contra mí, decidí emigrar y vivir exiliado mientras dominara la herejía.

Reconozco también como suma gracia y bondad de Dios, en lo que recuerdo, que no me permitiera vivir en pecado mortal más de veinticuatro horas, a pesar de que de joven -tan ingrato e indigno de misericordia- le ofendí mortalmente muy a menudo.

Pero aún con más frecuencia, ya desde la infancia, la Majestad divina despertaba en mí vehementes sentimientos y afectos con gran turbación de mi espíritu. Así, con diez años, mi madre me emplazó a prepararme para la sagrada comunión; y siempre que salía al campo para pensar en la magnitud de este misterio y pedir a Dios que me hiciera digno de tal don, de pronto sobrecogía mi mente una apacibilidad tan inmensa que rompía a llorar nadando en lágrimas. Esta moción se prolongaba algún tiempo, y con gran fruto (espero) me confesaba y comulgaba. Y desde entonces hasta el día de hoy me han ocurrido muchas cosas similares en Francia e Inglaterra, y en España, especialmente después de hacer el voto de castidad. Por no referir muchas, en España durante varios días se me ofreció una representación de Nuestro Señor Crucificado, tan impreso en mi memoria que siempre lo tenía presente salvo durante el sueño; gracia que acabé perdiendo por ingrato, por no valorarla como era debido y por no afanarme en conservarla.

Cuando leía la vida de San Benito escrita por San Gregorio, me deshacía en muchas lágrimas, y la mayor parte de la noche la paz y dulzura interior me invadían hasta vencerme el sueño. Ya después de ser admitido en la Sociedad, con mayor frecuencia y aún más abundancia, gocé de tales favores, y en esas ocasiones me parecía arder enteramente en amor divino. Incluso una noche orando en mi cama sin poder dormir, me pareció que algo como un río -no: un torrente- arrollaba mi corazón, llenándome de un deleite inenarrable, que me hacía saborear la presencia divina en mi alma. Con enorme gozo comencé a alabar a Dios anegado en lágrimas: no hacía más que repetir: «bienvenido Dios mío, bienvenido» y agradecer tan dulce encuentro. 


\section{LÍA VIGURIA GUERENDIÁIN}

Otra vez también en la noche de la Natividad del Señor decía la misa en el Colegio de los Ingleses, y al distribuir la sacrosanta Eucaristía a los que la deseaban, me sobrevino tal gozo y tantas ganas de llorar que no pude continuar la comunión, ni decir lo que faltaba de la misa. Pedí a Dios que me quitara ese ímpetu: no podía continuar la misa, ni siquiera leer en silencio lo que quedaba; lloraba hasta con hipo. Aquella alegría santa y felicidad duró dos o tres días. Esto da muestras de cuánta era la bondad y misericordia de Dios conmigo, mísero e ingrato pecador.

Finalmente, Dios me concedió una gracia singularísima poniéndome bajo la protección de su madre santísima durante todo el curso de mi vida. Lo he experimentado especialmente en sus fiestas, en muchas y grandes necesidades espirituales y temporales, como en vivir el voto de castidad que hice en su honor. También ante una calumnia ciertamente grave y un falso testimonio levantado contra mí en Bélgica que amenazaba con poner fin a mi vida. También en muchos peligros por mar y tierra sentí el manifiesto auxilio de la Santísima Madre, de modo que con razón podría yo decir lo que de sí mismo solía decir, en su profundísima humildad, mi Santo Padre Ignacio. Estas dos cosas a la vez no pueden darse en ningún otro hombre: haber recibido de Dios tantas y tan excelsas gracias y haber sido no menos ingrato hacia la divina Majestad.

Sobre lo último que se me requiere, respondo que he recibido mucha paz y edificación en todo lo que veo en la praxis del Instituto de la Sociedad, que tengo la firme esperanza de que por medio de lo dispuesto en ella llegaré al fin que persigo: mi salvación y la de mis próximos. Alabado sea siempre Jesucristo Señor Nuestro y su Santa y Dulcísima Madre.

\section{Hasta aquí lo que Fitzherbert dice de sí.}

En la última etapa de su vida deja constancia en un escrito su afán y solicitud por obtener las indulgencias:

Yo, Thomas Fitzherbert, sacerdote de la Compañía de Jesús, de ochenta y siete años, en medio de las asiduas enfermedades - a tal punto graves que a diario espero incluso que llegue el día de mi traslado- deseo ofrecer con todas las fuerzas que me restan el sufrimiento por las públicas y generales necesidades de la Iglesia. Y ofrezco a Jesucristo Señor Nuestro, en unión a su Sacratísima Pasión, todos los dolores corporales y cualquier molestia de mi enfermedad, las que sufro y vaya a sufrir hasta la hora de mi muerte por la paz de la Iglesia y la propagación de la fe católica, por las intenciones de Nuestro Santísimo Señor Urbano VIII, según la Bula del Jubileo, emitida recientemente por Su Santidad. Ya que por mi debilidad no puedo asumir otras penitencias corporales, he decidido rezar el rosario de la Santísima Virgen María junto con los siete salmos penitenciales y las letanías, cada día (con ayuda de la gracia divina) durante este tiempo de cuaresma, siempre que la vida y fuerzas me permitan, lo cual dejo al juicio de mi confesor. 


\section{REFERENCIAS BIBLIOGRÁFICAS}

\section{Fuentes primarias}

FITZHERBERT, Thomas, The first part of a treatise concerning policy, and religion Wherein the infirmitie of humane wit is amply declared, with the necessitie of Gods grace, and true religion for the perfection of policy; and by the way some political matters are treated; diuers principles of Macchiauel confuted... with a confutation of the arguments of atheists, against the prouidence of God... Written by Thomas Fitzherbert Esquire, and Catholique priest, for the benefite of young statists, Dowai, Laurence Kellam. M. DC. VI (1606).

FITZHERBERT, THOMAS, An sit vtilitas in scelere vel de infelicitate principis Macchiauelliani, contra Macchiauellum et politicos eius sectatores. Autore D. Thoma Fitzherberto, nobili Anglo Sacerdote. Ad illustriss. et excellentiss. principem D. Franciscum de Castro, comitem de Castro, Ducem Taurisanum etc., Romae, apud Gulielmum Facciottum, MDCX (1610).

DE Nieremberg, Iván Eusebio, Obras y dias. Manual de Señores y Príncipes, en que se propone con su pureza y rigor la especulacion y execucion politica, economica y particular de todas virtudes compuesto por el padre Iuan Eusebio Nieremberg, de la Compañia de Iesus, en Madrid, por la Viuda de Alonso Martín, 1629.

Machiavelli, Niccolò, Principe di Niccholo Machiauello al Magnifico Lorenzo Piero di Medici. La uita di Castruccio Castracani da Lucca a Zanobi Buondelmonti et a Luigi Alemanni descritta per il medesimo. Il modo che tenne il duca Valentino per ammazar Vitellozo, Oliuerotto da Fermo il S. Paolo et il duca di Grauina Orsini in Senigaglia descritta per il medesimo, Roma, per Antonio Blado d'Asola, 1532.

Machiavelli, Niccolò, Principe di Niccholo Machiauello al Magnifico Lorenzo Piero di Medici. La uita di Castruccio Castracani da Lucca a Zanobi Buondelmonti et a Luigi Alemanni descritta per il medesimo. Il modo che tenne il duca Valentino per ammazar Vitellozo, Oliuerotto da Fermo il S. Paolo et il duca di Grauina Orsini in Senigaglia descritta per il medesimo. I ritratti delle cose della Francia, et della Alamagna per il medesimo, nuovamente aggiunti, In Firenze per Bernardo di Giunta, 1532.

MaCHIAVELli, Niccolò, Ad Laurentium Medicem de Principe libellus, nostro quidem seculo apprime utilis \& necessarius, non modo ad principatum adipiscendum sed \& regendum \& conservandum. Nunc primum ex Italico in Latinum sermonem uersus per Syluestrum Telium Fulginatem, Basileae apud Petrum Pernam, 1560. Primera edición de Il Principe en latín.

Nifo, Agostino, Augustini Niphi Medice Philosophi Suessani de Regnandi Peritia ad Carolum. VI. Imper: Caesarem Semper Augustum, Neapoli in aedibus dominae Catherinae de Siluestro, 1523. Traducción libre al latín de Il Principe, cuyo autor ha sido acusado de plagio.

\section{Fuentes secundarias}

ANGLO, Sidney, Machiavelli - The First Century: Studies in Enthusiasm, Hostility, and Irrelevance, Oxford, 2005.

À WOOD, Anthony, Athenae Oxonienses. An Exact History of all the Writers and Bishops who have had their Education in the most Ancient and Famous University of Oxford, from The Fifteenth 


\section{LÍA VIGURIA GUERENDIÁIN}

Year of King Henry the Seventh, Dom. 1500, to the End of the Year 1690. (...). The First Volume, Extending to the 16th. Year of King Charles I. Dom. 1640, 1691.

BÉNICHOU, Léa, Informadores y confidentes de los embajadores de Felipe III en Roma, en Tiempos Modernos, t. 8, 35/2, 2017.

BIRKHEAD, George y QUESTIER, Michael C. (ed.), Newsletters from the Archpresbyterate of George Birkhead, vol. 12 (Camden Fifth Series), Cambridge, 1998.

BURKE, John, A Genealogical and Heraldic History of the Commoners of Great Britain and Ireland, Enjoying Territorial Possessions or High Official Rank, but Uninvested with Heritable Honours, t. 1, London, 1833.

CAMM, Bede, Forgotten Shrines: an Account of some old Catholic Halls and Families in England, and of Relics and Memorials of the English Martyrs, London, 1910.

Courtenay, Thomas, An Eulogium of the Rev. F. Thomas Fitzherbert, written by F. Thomas Courtenay, Rector of the English College at Rome, the day after the said F. Fitzherbert's decease, en The Catholic Spectator, t. 1, London, 1824.

DE Alegambe, Philippe, Bibliotheca Scriptorum Societatis Iesu, Post excusum Anno 1608 Catalogum Petri Ribadeneirae Nunc hoc novo apparatu librorum ad annum reparatae salutis 1642 editorum concinnata et illustrium virorum elogiis adornata; Accedit Catalogus Religiosorum Societatis Iesu, ... I a Philippo Alegambe, Antverpiae, 1643.

DoDD, Charles, The Church History of England, from the Year 1500, to the Year 1688. Chiefly with Regard to Catholicks: Being a Complete Account of the Divorce, Supremacy, Dissolution of Monasteries, and First Attempts for a Reformation Under King Henry VIII... in Eight Parts, t. 2, Brussels [i.e. London*], 1739.

DodD, Charles y TiERney, M. A. (ed.), The Church History of England, from the Year 1500, to the Year 1688, London, 1840.

EIRE, Carlos M. N., Reformations: The Early Modern World, 1450-1650, New Haven-London, 2016.

FERnández Luzón, Antonio, Lorenzo IV Suárez de Figueroa y Córdoba (1559-1607), en Real Academia de la Historia, http://dbe.rah.es/biografias/15663/lorenzo-suarez-de-figueroa, accedida el 17/09/2018.

FOLEY, Henry, Records of the English province of the Society of Jesus: Historic facts illustrative of the labours and sufferings of its members in the sixteenth and seventeenth centuries. Second, Third and Fourth Series, London, 1875.

GILberT, Allan H., Machiavelli's Prince and its Forerunners. The Prince as a Typical Book de Regimine Principum, Durham, 1938 ${ }^{1968 \mathrm{rp}}$.

KIPPIS, Andrew, Biographia Britannica: Or The Lives Of The Most Eminent Persons Who Have Flourished in Great Britain And Ireland, From the Earliest Ages, Down to the Present Times: Collected from the Best Authorities, Both Printed and Manuscript, And Digested in the Manner of Mr Bayle's Historical and Critical Dictionary, t. 3, Innys et allii London, 1750.

* [Ambas lecturas, Brussels y London, son correctas. Se debe a la prohibición y censura de imprimir libros católicos en suelo inglés; la imprentas clandestinas señalaban en la página de título un lugar del continente para pasar algo desapercibidas]. 
Maquiavelo, Nicolás, El Príncipe de Niccolò Machiavelli comentado por Napoleón Buonaparte. Milán, 1993***

MORE, Henry, Historia missionis Anglicanae Societatis Iesu, ab anno salutis, M.D. LXXX ad DCXIX et vice-provinciae primum, tum provinciae ad eiusdem saeculi annum XXXV collectore Henrico Moro, eiusdem Societatis Sacerdote, Audomari (Saint-Omer), 1660.

OLIVER, George, Collections Towards Illustrating the Biography of the Scotch, English, and Irish Members, S.7., 1838.

POLLEN, John Hungerford, Acts of English martyrs hitherto unpublished, London, 1891.

Pollen, John Hungerford (ed.), Unpublished Documents Relating to the English Martyrs, vol. 1: 1584-1603 (Catholic Record Society Record Series, t. 5), London, 1908.

PollnitZ, Aysha, Princely Education in Early Modern Britain, Cambridge, 2015.

PRAZ, Mario, Machiavelli in Inghilterra, ed altri saggi, Roma, 1943.

Vergara CIORDIA, Javier, La educación política en la Edad Media: el «Tractatus de morali principis institutione» de Vicente de Beauvais (1262/63): una apuesta prebumanista de la política, Barañáin, 2010.

VERGaRa CIORDIA, Javier, El «De Eruditione Filium Regalium»: un tratado de pedagogía sistemática para la educación de príncipes en la Edad Media, en ESE, Estudios sobre educación, 19, 2010, pp. 77-96.

Vergara Ciordia, Javier, Tratado sobre la formación de los hijos de los nobles (1246) Vicent de Beauvais; AdEVA MARTín, Ildefonso y VERGARA CIORdia, Javier (ed. lit.), Madrid, 2011.

VIGURIA GUERENDIÁIN, Lía, An sit utilitas in scelere: Librum impressione dignissimum. Una censura de Maquiavelo, en VERGARA CIORDIA, Javier y SALA VILlaVERDE, Alicia (coords.), Censura y libros en la Edad Moderna, Madrid, 2017, p. 127-144.

VIGURIA GUERENDIÁIN, Lía, Thomas Fitzherbert: una apuesta inglesa por la pedagogía católica en la segunda mitad del siglo XVI, en NEGRÍN FAJARDO, Olegario; VERGARA CIORDIA, Javier y Vilanou Torrano, Conrado (dirs.), Madrid, 2018, pp. 135-151.

VIGURIa GUERENDIÁIN, Lía, Virtus o scelus: ¿misma utilitas para el emperador?, en Edición y Traducción de Fuentes. Humanistas, belenistas y bebraístas en la Europa de Carlos V, Salamanca, en prensa (noviembre 2018).

*** Reproducción de la primera traducción española del texto de Maquiavelo comentado por Napoleón Buonaparte. El volumen con sus notas manuscritas fue hallado en el coche de Bonaparte después de la batalla de Mont Saint-Jean (Waterloo) el 18 de junio de 1815. Fue publicado en París en 1827. 



\section{HISTORIOGRAFÍA Y BIBLIOGRAFÍA}


